\title{
منظورية نيتشه النقدية للديمقراطية الحديثة \\ وجمهورها
}

\section{The Critical Nietzchean Perspective on Modern Democracy and its Public}

ملخص: مثلت المسألة الديمقراطية مشكلًا في الفلسفة السياسية الغربية عقب شبه التحرر

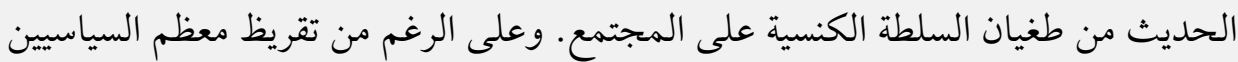

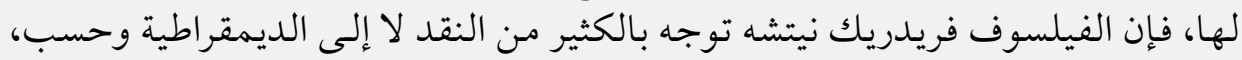

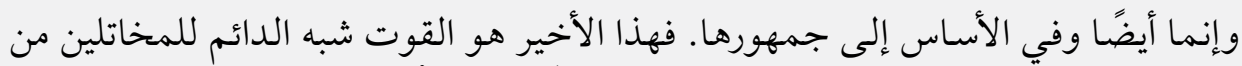

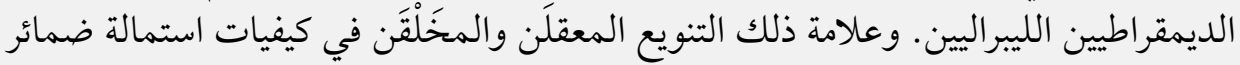

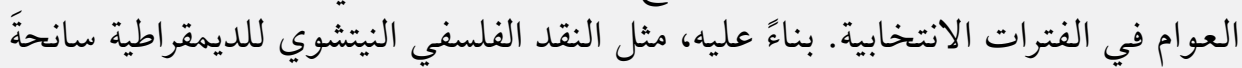

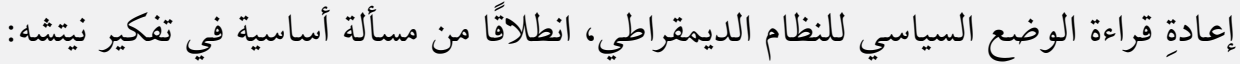

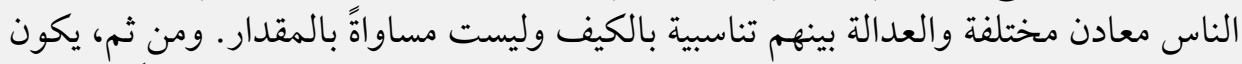

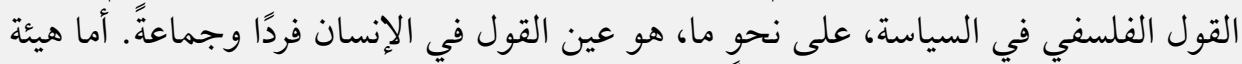

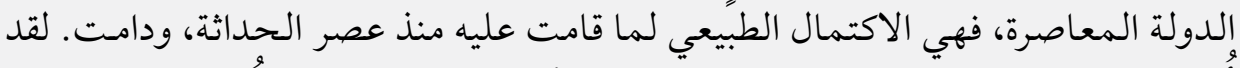

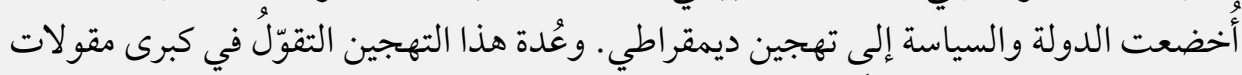

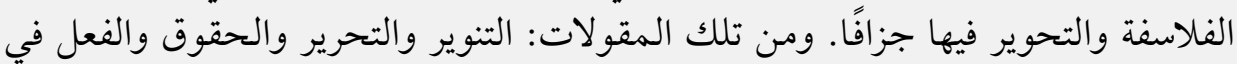

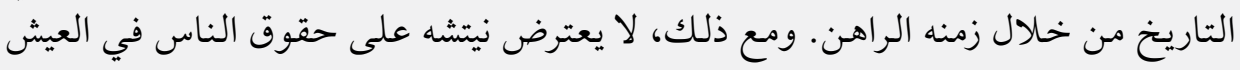

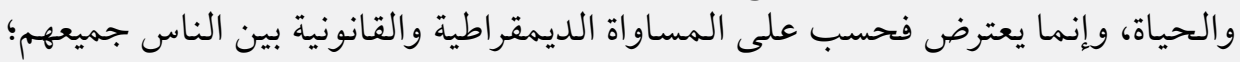

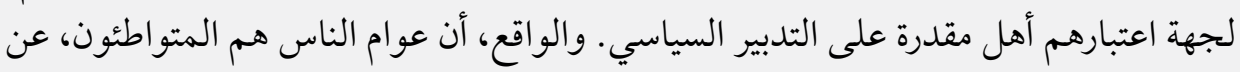
قصور وجبن وسذاجة، مع الساسة المنكلين بهم. كلمات مفتاحية: الديمقراطية، الجمهور، العوام، الدولة، الأرستقراطية، الأخلاق.

Abstract: After the modern quasi-liberation from the tyranny of the church's authority over society, the democratic issue represented a problem in Western political philosophy. Although most politicians praised it, the philosopher Nietzsche

$$
\text { * * أستاذ مساعد بقسم الفلسفة، كلية الآداب والعلوم الإنسانية، جامعة صفاقس، تونس. }
$$


directed a lot of criticism not only to democracy, but to its public as well. The latter is the permanent sustenance of the deceitful liberal democrats. The sign of this is the rationalized and ethicalized diversity of the methods they use to appeal to the public in electoral periods. Accordingly, the Nietzchean philosophical criticism of democracy represented an opportunity to re-read the political situation of the democratic system on the basis of a fundamental issue in Nietzsche's thinking: people are made of different metals and justice is proportionality in quality and not equality in amount. Hence, the philosophical statement in politics is, in a way, the same about the individual and the group. As for the structure of the contemporary state, it is the natural completion of what has been established and what has persisted since the era of modernity. Together, the state and politics have been subjugated to democratic hybridization. The instrument of this crossbreeding is the prolongation of major concepts that are haphazardly changed by the philosophers who employ them. Among those concepts: enlightenment, liberation, rights, and action in history through its current time. However, Nietzsche does not object to people's rights to live, but only to the democratic and legal equality between all people in terms of considering them capable of political management. In fact, lay people, in their failure, cowardice and naiveté, are complicit with the politicians who abuse them.

Keywords: Democracy, the Public, Commoners, the State, Aristocracy, People's Caliber, Intolerance, Political Ideology, Ethics.

\section{مقدمة}

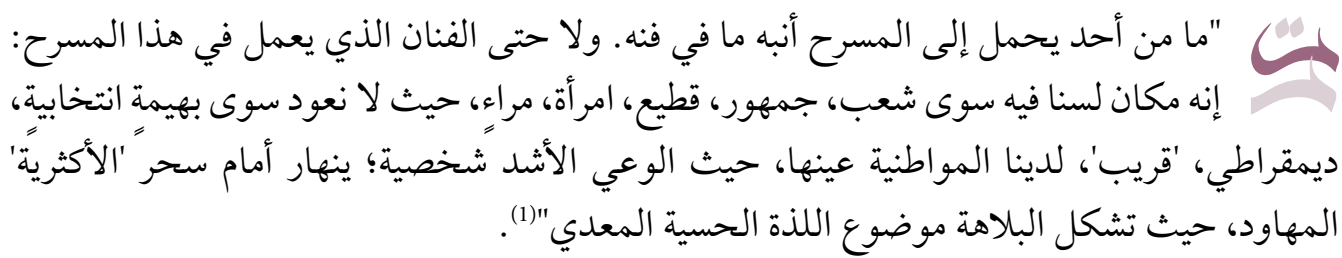

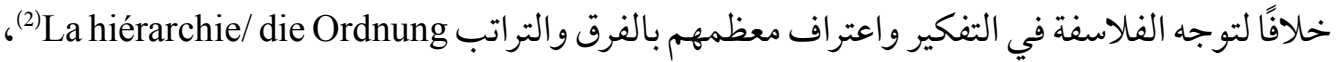
فإن أناس عصرنا يُجمعون، أو يكادون، على أفضلية الديمقراطية La démocratie/ die Demokratie

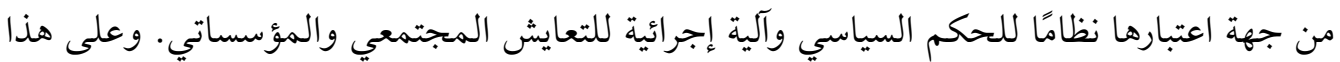
(1) فريدريك نيتشه، العلم الجذل، ترجمة سعاد حرب (بيروت: دار المنتخب العربي للدراسات والنشر والتوزيع، 2001)، فقرة

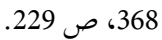

(2) لمزيد من النظر والتعمق في مسألة الدرجة والرتبة والمسافة بين الناس، يمكن الرجوع إلى النص كاملاً في المصدر الأصلي

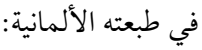

Friedrich Nietzsche, Ecce Homo: Wie man wird, was man ist, XIII: Der Fall Wagner-Ein Musikanten-Problem, Giorgio Colli \& Mazzino Montinari (eds.), Sämtliche Werke, Kritische Studienausgabe, $6^{\text {th }}$ ed. (Berlin $/$ New York: Deutscher Taschenbuch Verlag; München: Walter de Gruyter, 1988), § 4-10, pp. 362-364.

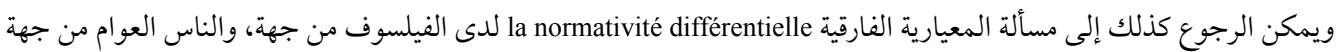

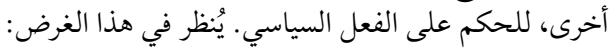

Stamatios Tzitzis, Nietzsche et les hiérarchies (Paris: L'Harmattan, 2008), p. 15. 
La démocratie النحو، يُعْقَد في الفكر السياسي، الحديث منه والمعاصر، أن الديمقراطية الشعبية populaire/ die Volksdemokratie

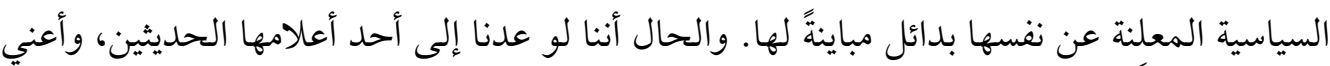

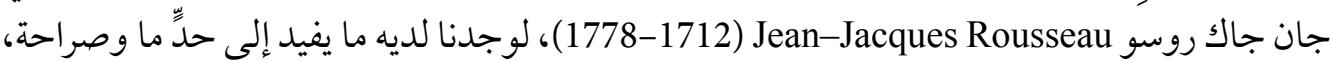

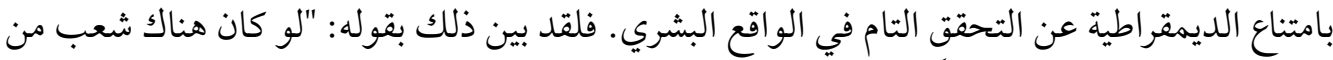

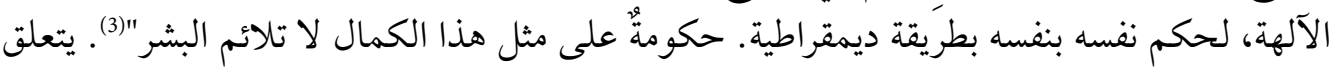

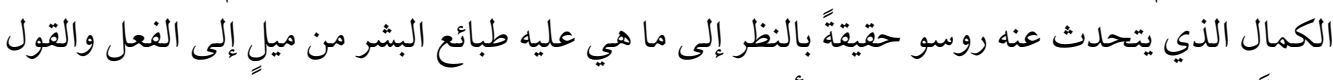
النزويَّن، والوقوع تحت وزر اجتذاب الأهواء السياسية.

بناء عليه، فإننا سنتبين مع فريدريك نيتشه Friedrich Nietzsche (1844-1900) كيف أن الديمقراطية

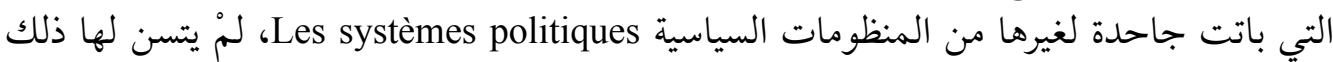
إلا عندما أضحت تنال من العقل السياسي الحاكم بأمره مقدارَ ما تناله من عقول العوام، وقد سيقَ فيقي بهم في الكثير من الأحيان إلى التعصب من أجلها. وتلكم الديمقراطية، في صيغتها الحديثة، هي في

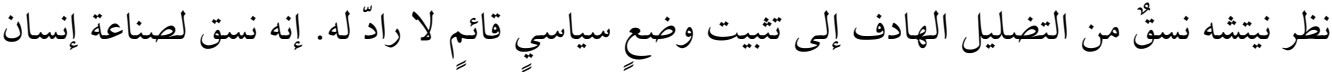

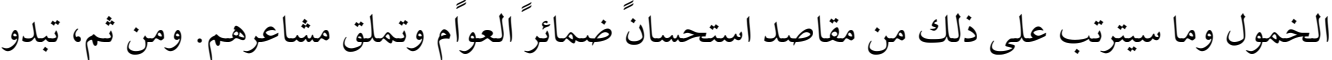
لنا، في هذا الاستهالال من البحث في نقد نيتشه للديمقراطية، كما لو كانت مفهومًا لغويَّا متوثنًا ونظامًا

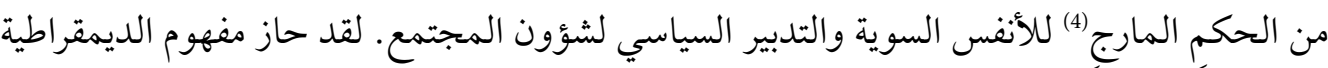

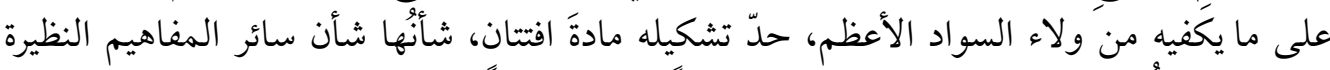

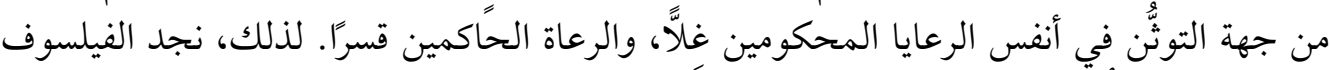

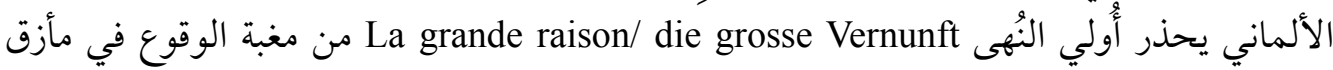
صناعة مفردات اللغة(5) الخادمة مجانًا للأوهام، مثلما هي الحال في عالَّم السياسة اليوم.

يترتب على ما سلف، من تحذير نيتشوي، التنبيهُ على سبيل تحصيل المناعة السياسية اللازمة نفعًا

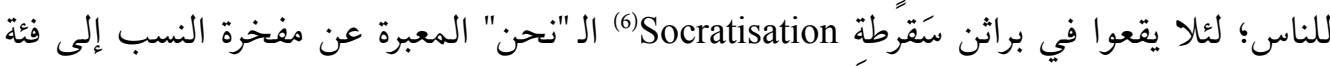

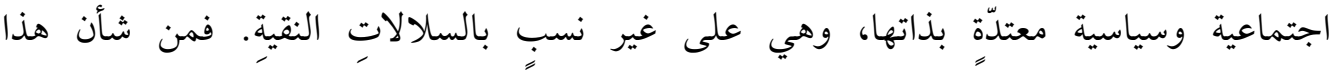
(3) جان-جاك روسو، في العقد الاجتماعي: أو مبادئ الحق السياسي، ترجمة عمار الجلاصي وعلي الأجنف (تونس: دار المعرفة للنشر، 1980)، ص 60 كان رون في

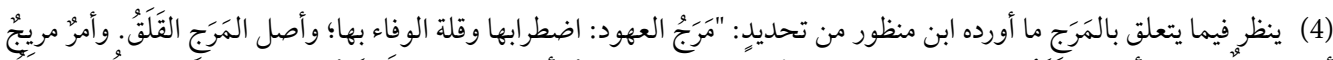

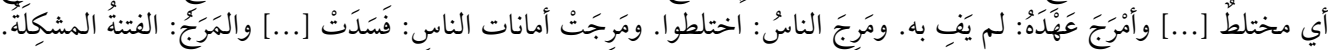

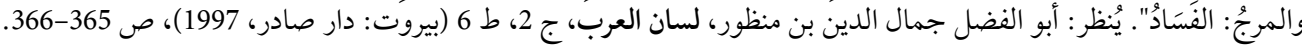

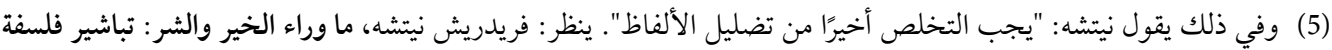

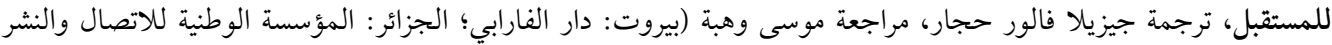

والإشهار، 2003)، فقرة 16، ص تر 39.

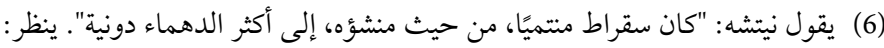
Friedrich Nietzsche, Crépuscule des Idoles ou Comment philosopher à coups de marteau, Jean-Claude Hémery (trad.), Euvres philosophiques complètes, vol. 8 (Paris: Gallimard, 2004), § 3, p. 70. 


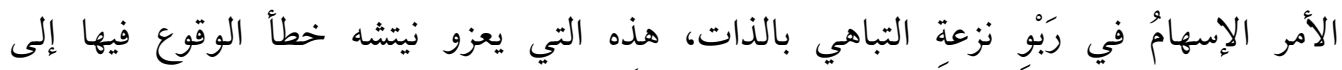

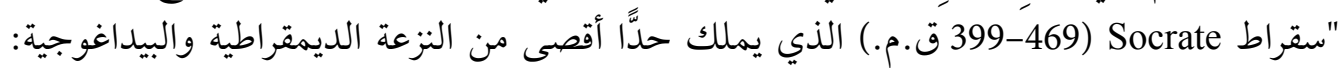

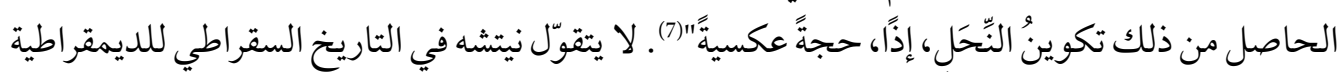

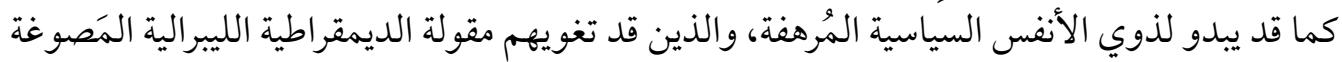

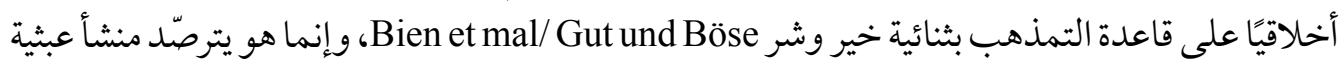

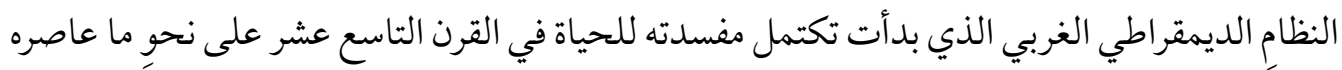

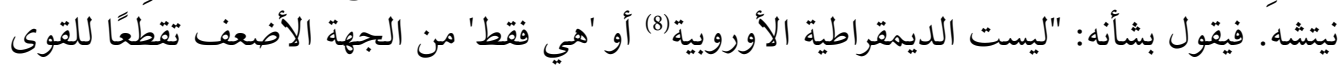

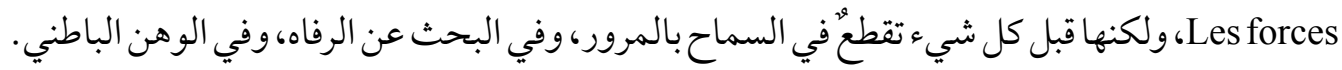

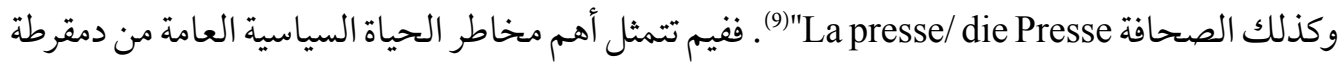

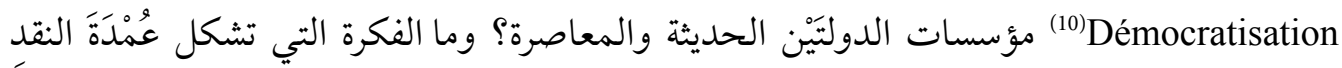

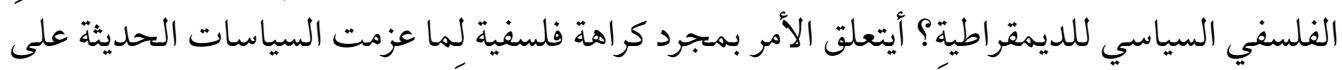

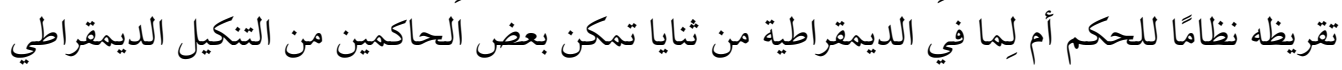

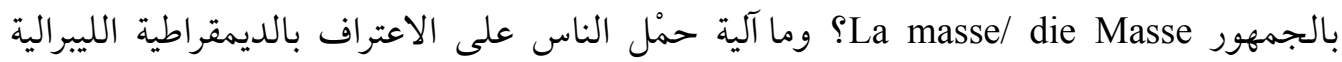
المغشوشة نسيكةً سياسية للدولة État/ Staat غير العادلة؟

\section{أولاً: كيان الدولة ومششكل الحياة السياسية العامة}

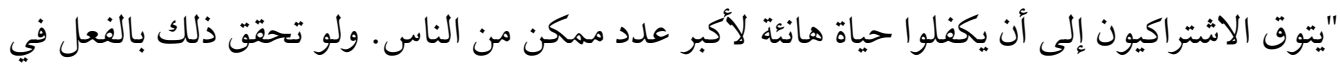

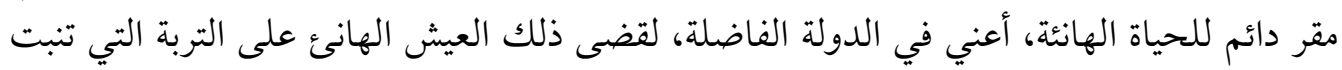

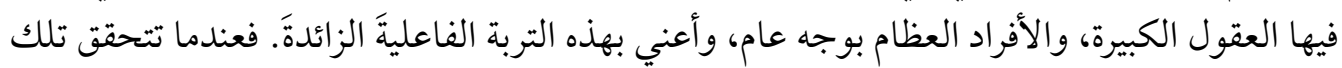

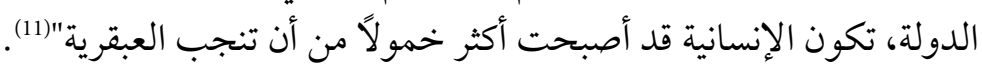

ما الذي يشرع من ناحية الفلسفة السياسية اعتراض نيتشه على هيئة الدولة الحديثة، وصيغ حياتها السياسية المخاتلة؟ وهل كان من أهل البصيرة السياسية القادرة على توقُع مآلات النظام السيثة السياسي

(7) Friedrich Nietzsche, Le livre du philosophe: Études théorétiques, Angèle Kremer-Marietti (trad.) (Paris: Garnier Flammarion, 1991), § 175, p. 113.

$$
\text { ينظر قول أوليفر ربول (1925-1992): "و إنما هي أيضًا سياستنا، مجتمعنا، حضارتنا هي التي عليها يحتج". }
$$

Olivier Reboul, Nietzsche critique de Kant (Paris: PUF, 1974), p. 157.

(9) Friedrich Nietzsche, Fragments posthumes: Automne 1884 - automne 1885, Michel Haar \& Marc Buhot De Launay (trad.), Giorgio Colli \& Mazzino Montinari (eds.), Euvres philosophiques complètes, vol. 11 (Paris: Gallimard, 1982), p. 204.

ينظر كذلك المرجع نفسه، الفقرة التالية.

(10) Friedrich Nietzsche, Fragments posthumes: Automne 1887-mars 1888, Pierre Klossowski \& Henri-Alexis Baatsch (trad.), Euvres philosophiques complètes, vol. 13 (Paris: Gallimard, 2006), p. 144.

(11) Friedrich Nietzsche, Humain, trop humain: Un livre pour esprits libres, Robert Rovini (trad.), Giorgio Colli \& Mazzino Montinari (eds.), Euvres philosophiques complètes, vol. 3 (Paris: Gallimard, 1988), § 235, p. 183. 


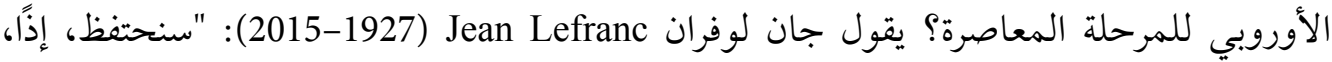

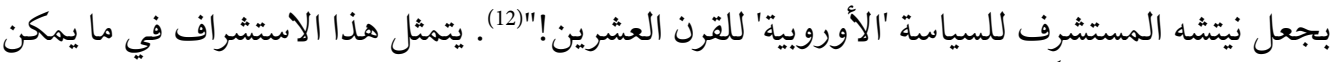

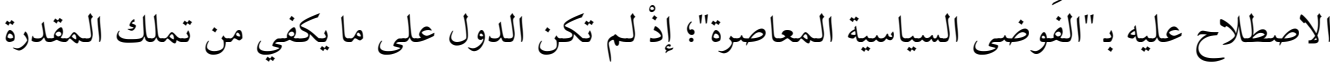

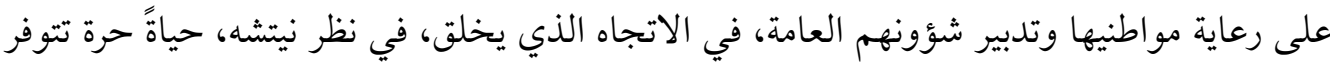

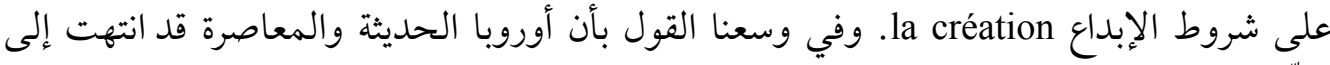

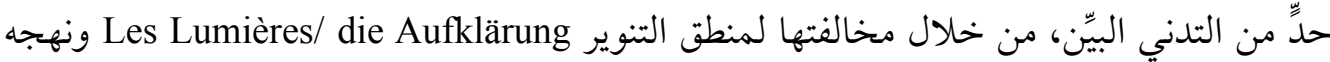

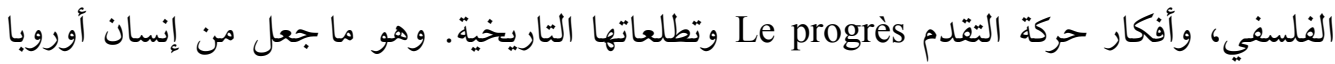

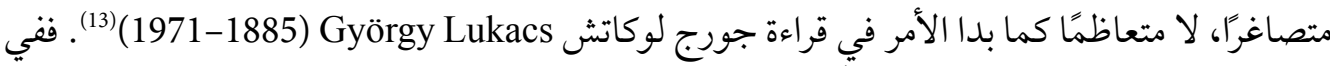

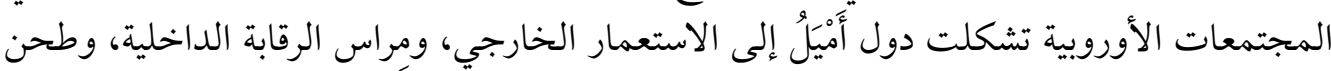

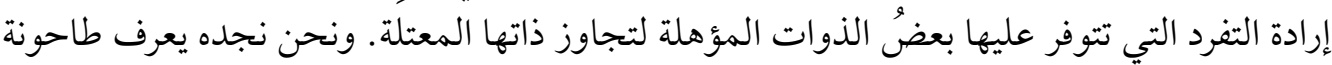

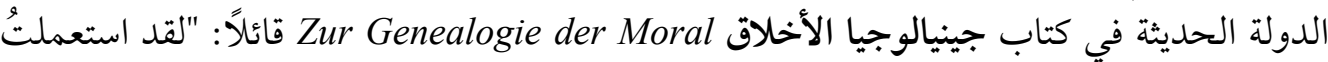

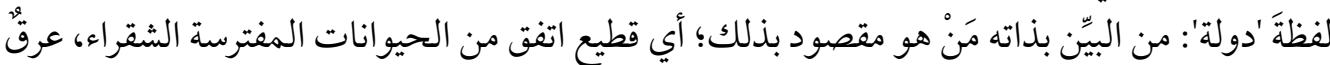

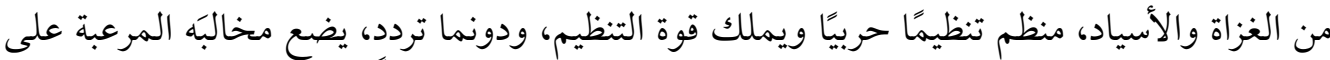

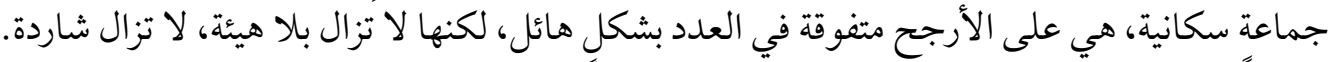

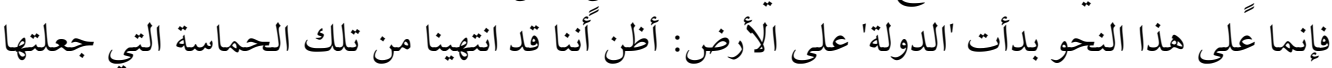

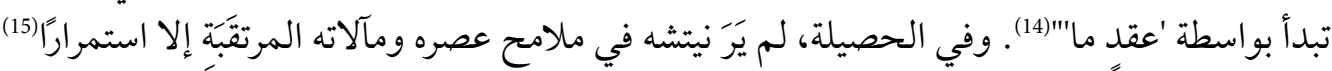

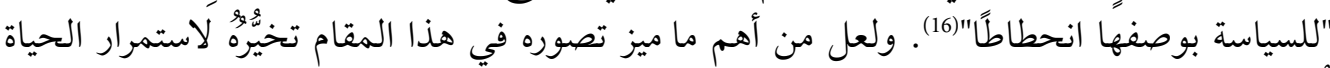

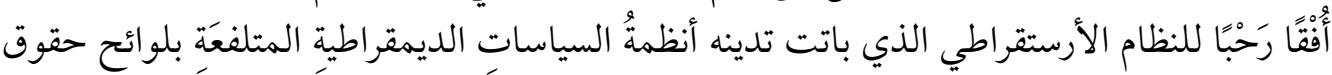

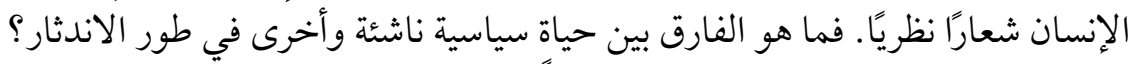

يتمثل الرد النيتشوي على هذا السؤال في دعوته ذوي الكياسة السياسية إلى التمبيز التاريخي بين حياة

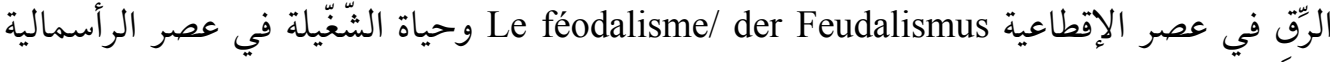
Le capitalisme/ der Kapitalismus

(12) Jean Lefranc, Comprendre Nietzsche (Paris: Armand Colin, 2003), p. 172.

(13) ينظر قوله: "لا تمثل الديمقراطية في نظر نيتشه 'سقوط الدولة'، وإنما أيضًا وقبل كل شيء 'إفساد أوروبا وتصغير الإنسا الإنسان

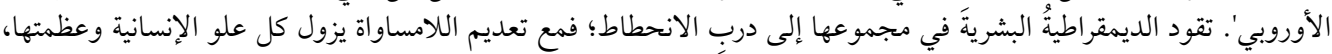
وتظهر لأمبالاة بليغة تجاه كل القيم".

"Nietzsche. L'antisystème," Philosophie Magazine, Hors-série, vol. 26 (été 2015), p. 121.

فريدريتش نيتشه، في جنيالوجيا الأخلاق، ترجمة فتحي المسكيني، مراجعة محمد محجوب (تونس: المركز الوطني للترجمة،

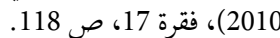

نلاحظ أن نيتشه استخدم في النص الألماني صفة "الانحطاط" باللسان الفرنسي. ينظر:

Friedrich Nietzsche, Fragments posthumes: Début 1888-début janvier 1889, Jean-Claude Hémery (trad.), CEuvres philosophiques complètes, vol. 14 (Paris: Gallimard, 2008), p. 221; Friedrich Nietzsche, Sämtliche Werke: Kritische Studienausgabe in 15 Bänden, Giorgio Colli \& Mazzino Montinari (eds.) (Munich: Deutscher Taschenbuch Verlag, 1980), p. 467.

(16) Ibid. 
بنيَّهُما. ونجد نيتشه يقر في هذا السياق بأنه "ينبغي، مع ذلك، على كل امرئ أن يوقن بأن حياة العبيد

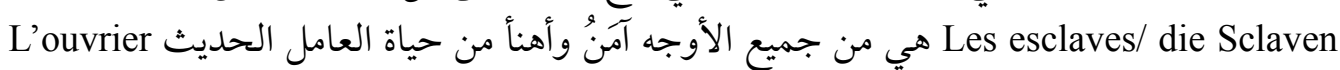
moderne/ der moderne Arbeiter

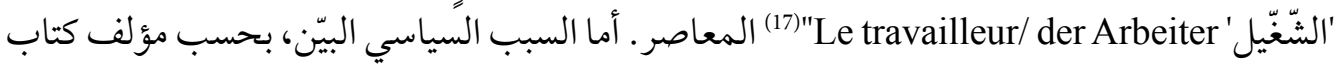

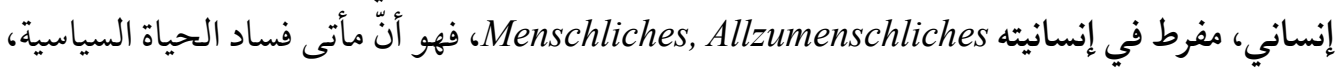

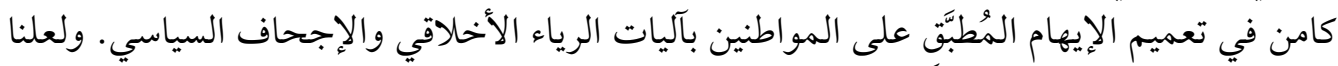

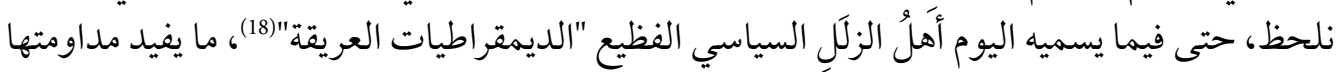

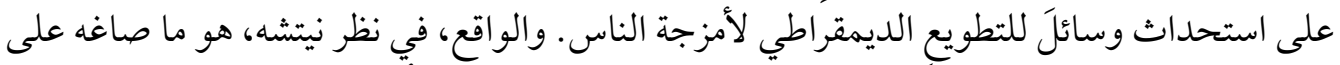

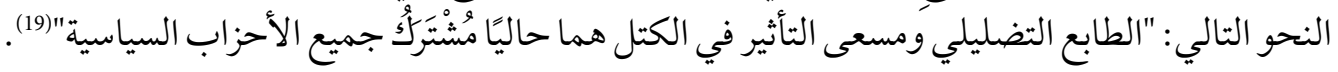

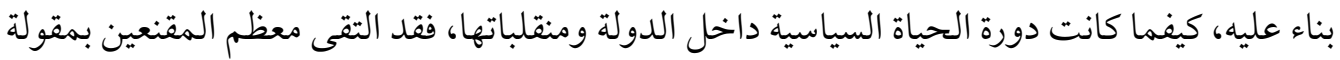

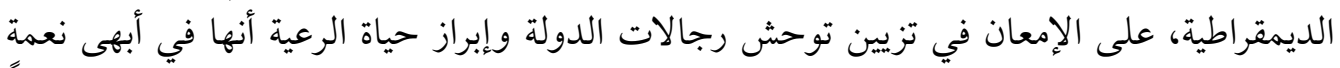

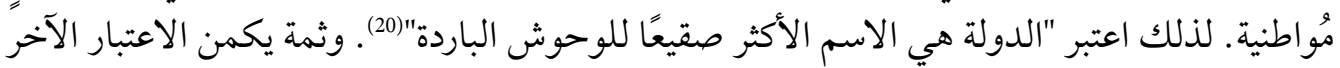

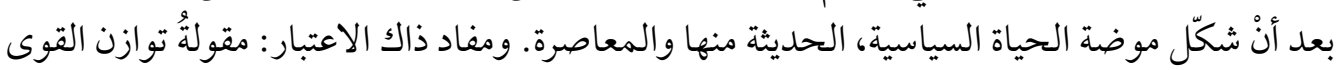

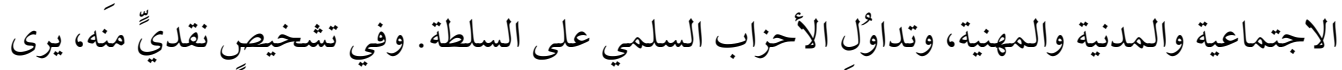

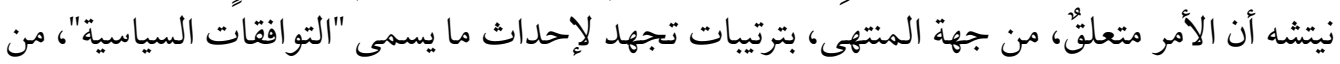

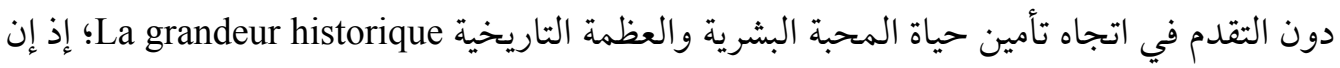

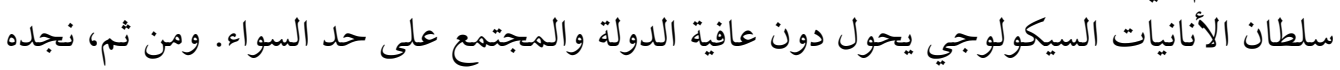

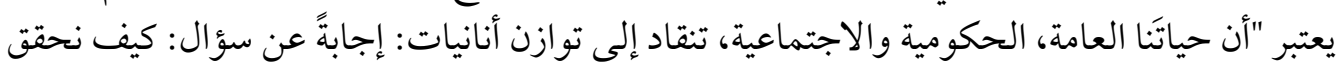

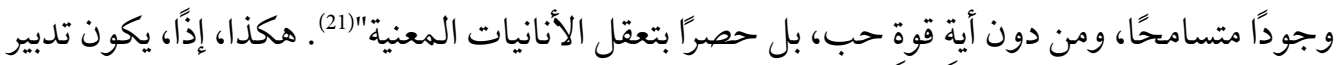

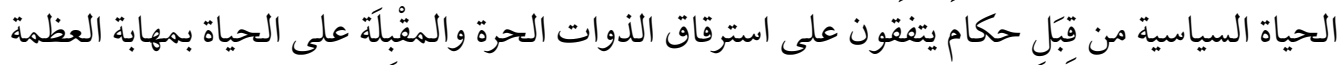

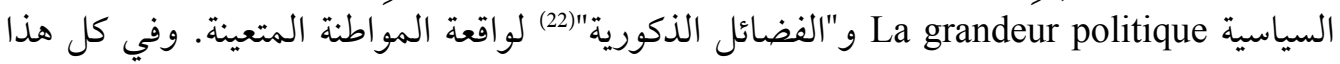

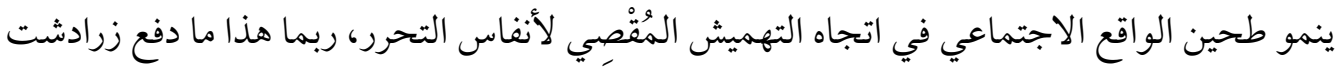
Zarathoustra

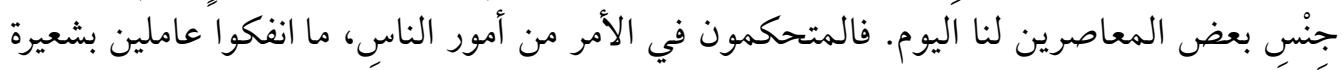

(17) Nietzsche, Humain, trop humain, § 457, p. 273.

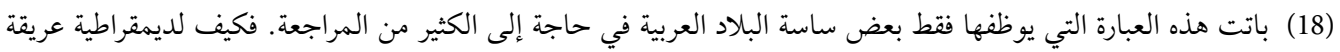

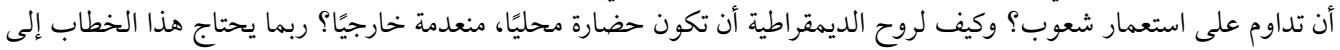

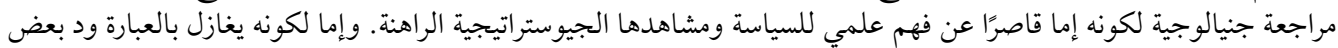
الأنظمة والقائمين على ثقافتها الإعلامية ليتموقع.

(19) Nietzsche, Humain, trop humain, § 438, p. 261.

(20) Friedrich Nietzsche, Ainsi parlait Zarathoustra: Un livre qui est pour tous et qui n'est pour personne, Maurice De Gandillac (trad.), Euvres philosophiques complètes, vol. 6 (Paris: Gallimard, 2004), p. 61.

(21) Friedrich Nietzsche, Fragments posthumes: Été 1872-Hiver 1873-1874, Pierre Rusch (trad.), Euvres philosophiques complètes, vol. 2 (Paris: Gallimard, 1990), p. 195.

(22) Nietzsche, Crépuscule des Idoles, § 28, p. 65. 
التقية السياسية، أي المخاتَكة، أو ما يسمى أحيانًا التكتيك؛ إذ يقرر الواحد منهم استقبالَ الشأن العام بنهِم الإنسان الجشع وقد تظاهر بكونه راغبًا عن مغانم الحياة السياسية. وفي ما يناظر هذا لدا السياق،

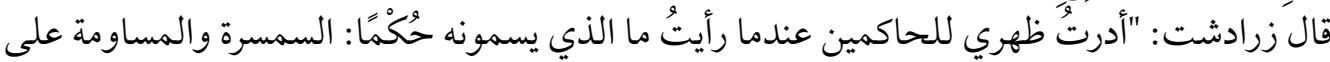
السلطة، مع الرعاع!"(23). فما الذي يوجد في آليات اشتغال الدولة من تشعبات خَطرِّة؛ ليثير حفيظة

نيتشه السياسية؟

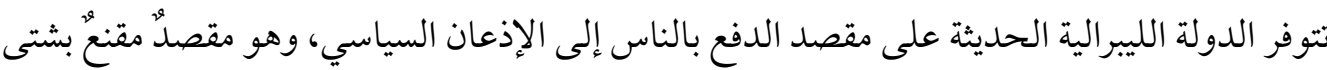

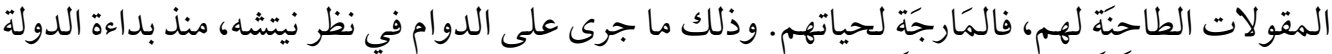

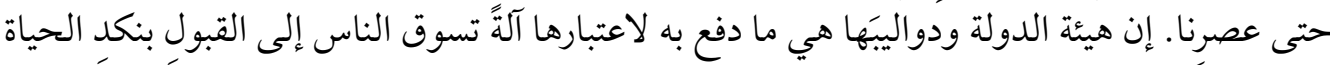

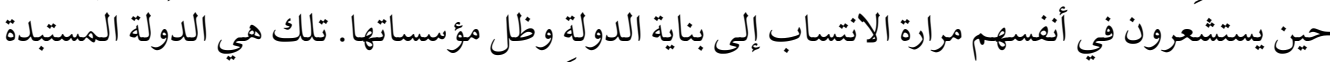
التي ما ترددت قط في سحقهم بكل صنوف الدناءة والمهانة. وفي متابعته لمأتى هيئة الدولة يقول:

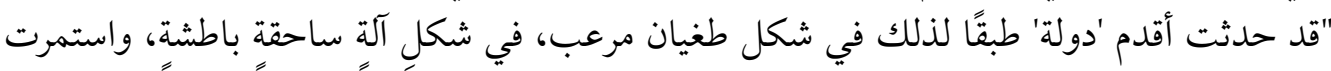

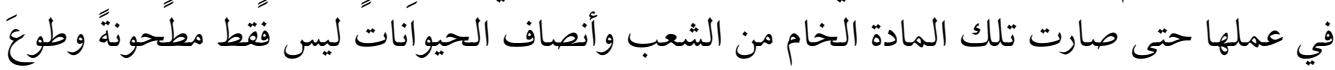

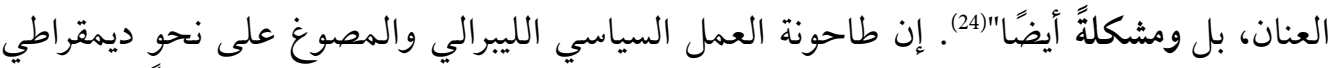

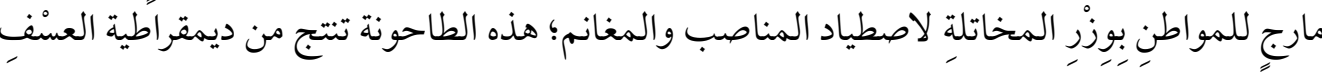

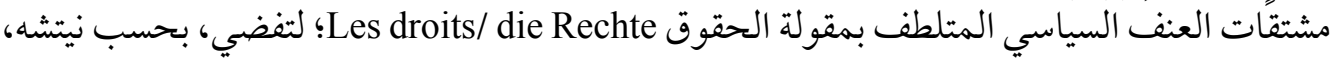

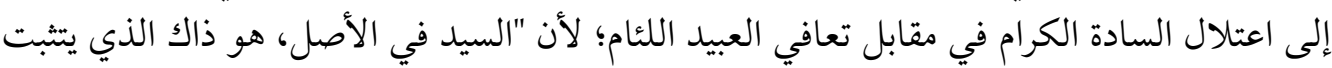
بوصفه مقتدرًا، بوصفه محاربًا، بوصفه أرفحَ. إن الحَسَنَ مفهوم سياسي وإيجابي مباشرة؛ إنه إثبات

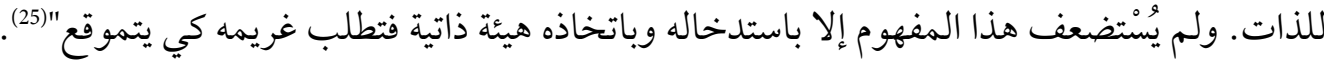
والخلاصة من السياسة النيتشوية، تبعًا لتشخيصه صلَفَ الدولة الليبرالية المعاصرة، أن إشاعةَ الذكر فئه بأخلاقيات سياسة الخير والشر قد أفضت إلى "عصور فساد"(26). والآثم في عصور من هذا القبه القبيل

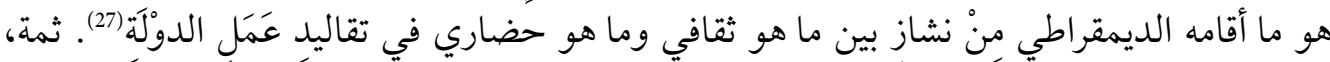

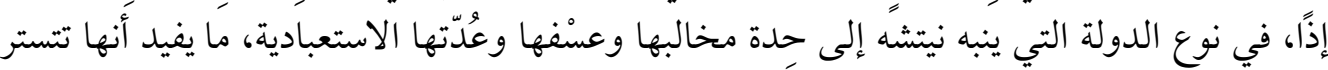

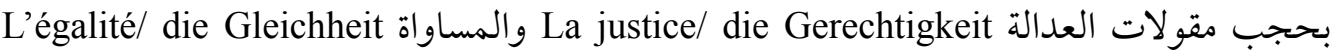
والديمقراطية؛ لكي تُمعن في تثيتِ روح الضغينة لدى السواد الأعظم. ولذاك الإمعان مسحة التنكيل (23) فريدريش نيتشه، هكذا تكلم زرادشت: كتاب للجميع ولغير أحد، ترجمة علي مصباح (كولونيا/ بغداد: منشورات الجمل،

(25) André Clair, Éthique et humanisme: Essai sur la modernité (Paris: Cerf, 1989), p. 118.

(26) Nietzsche, Fragments posthumes, vol. 14, p. 239.

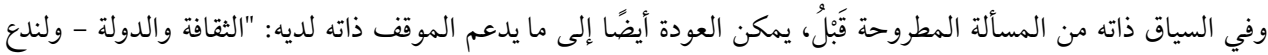

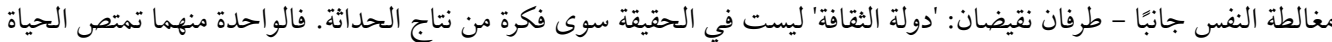

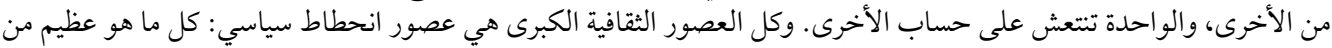

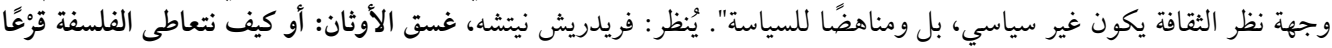

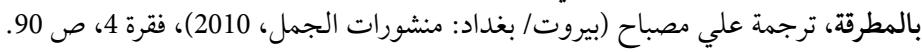


الليّن الذي هو شرط ديمومة الديمقراطية الضاغطة la démocratie massive على العازمين التحرر وانتزاع حقهم في التمتع بمشاعر الكرامة البشرية.

\section{تُانيًا: تهافـت تصور الديمقر اطية الليبرالية للعدالة والمساواة} "الحكم. بعضُ الحكام يحكمون لأنهم يجدون في الحكم متعة، وآخرون يحكمون لكيلا يصبحوا

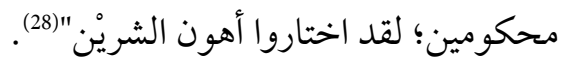

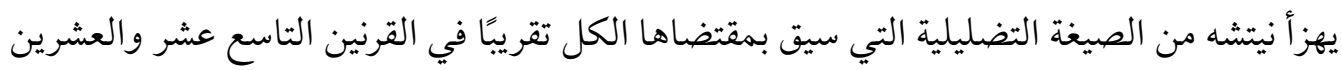

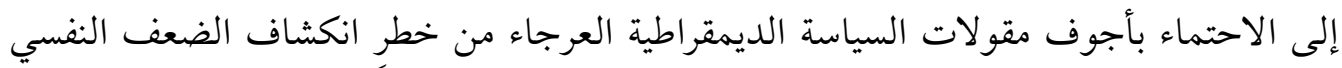

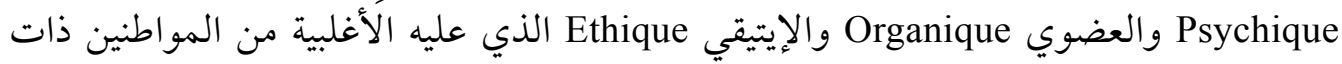
الآراء المارجة. فضلاً عن الأخطاء النظرية شبه الدائمة في المقاربات المحلية والعالمية للاقتصاد السياسي Léconomie politique. إن ما يبسطه نيتشه للتظنن به هو "نقد لـ 'العدالة' ول 'المساواة ولنه أمام القانون' La loi/ das Gesetz. وبالفعل، ما الذي يجب أن يقصيه هذا؟ الضغط، النيه الكراهية، الحقد، ولكن من الخطأ الاعتقاد أننا بهذا نزداد من 'السعادة'"(29). من المعلوم أن نيتشه، مثل غيره

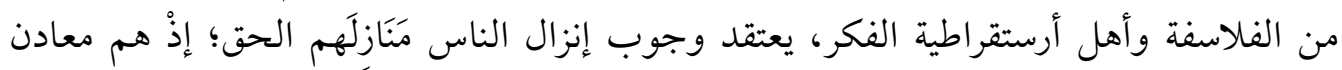

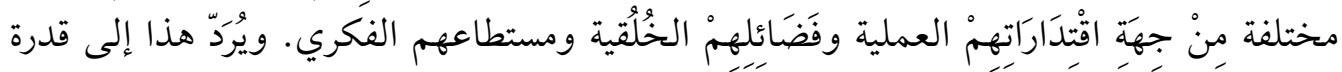

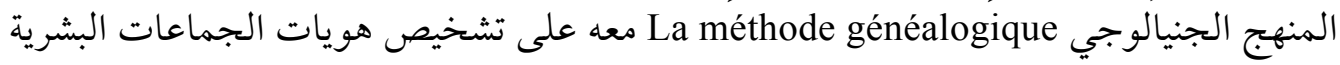

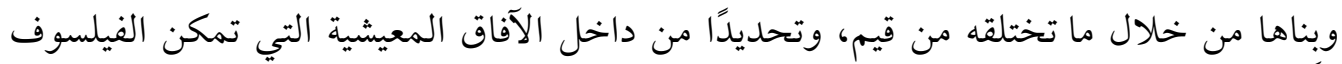

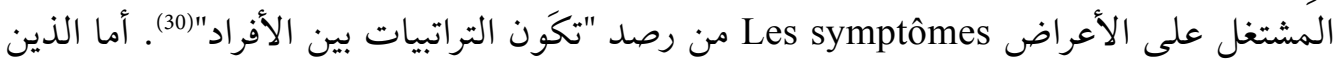

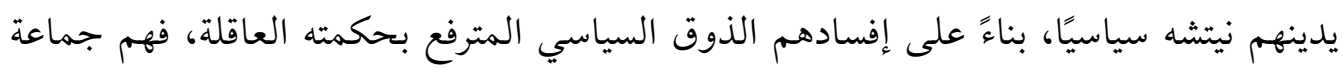
العبيد (31)

$$
\text { فريدريك نيتشه، الفجر، ترجمة محمد الناجي (الدار البيضاء: أفريقيا الشرق، 2013)، فقرة 181، ص } 131 .
$$

(29) Friedrich Nietzsche, Fragments posthumes: Automne 1885 -automne 1887, Julien Hervier (trad.), Cuvres philosophiques complètes, vol. 12 (Paris: Gallimard, 2007), p. 227.

(30) Dorian Astor, Deviens ce que tu es: Pour une vie philosophique (Paris: Autrement, 2016), p. 59.

ولنظلاطلاع أكثر على ما يتعلق بضرورة تميز الأفراد في توجهاتهم بما يُحررهم من تنزيل معظم الزعماء السياسيين لهم منزلة "البهائم"،

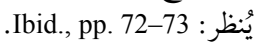

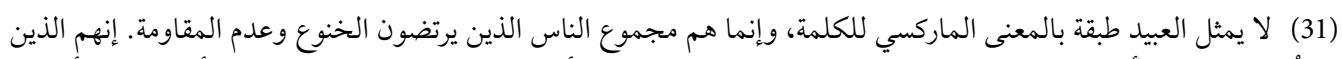

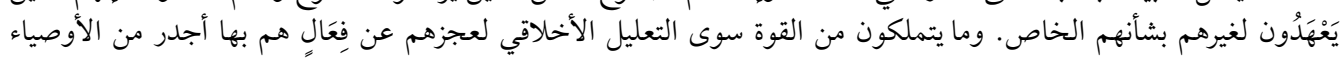

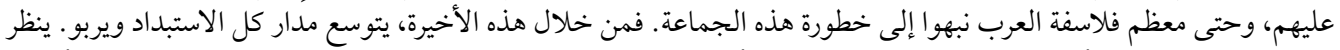

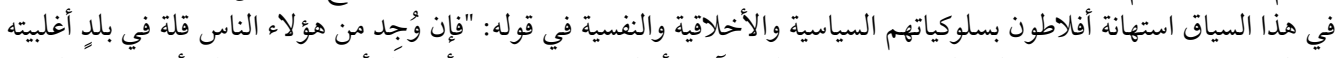

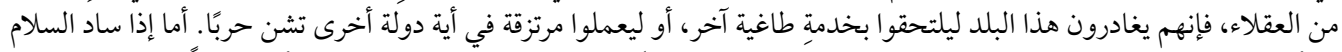

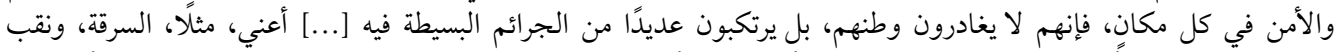

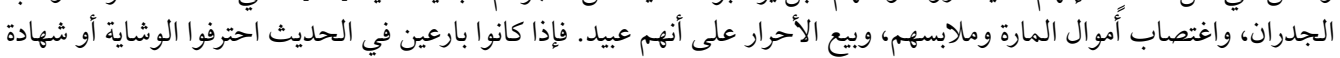

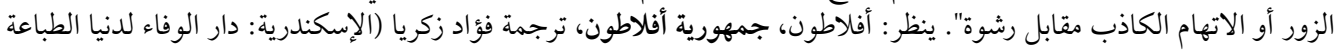




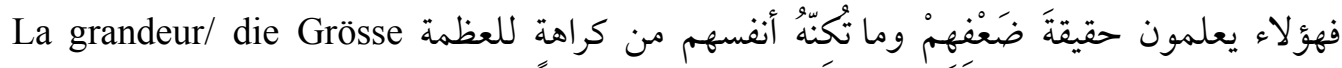

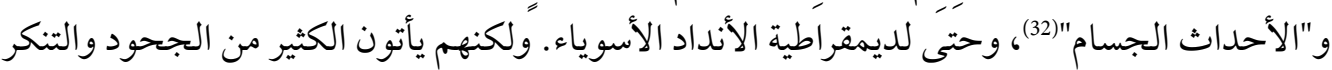

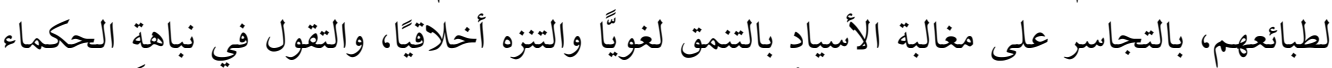

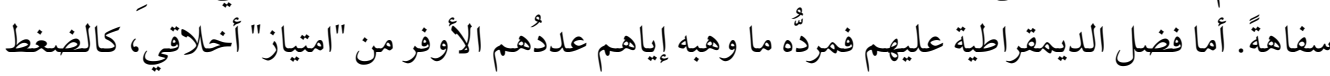

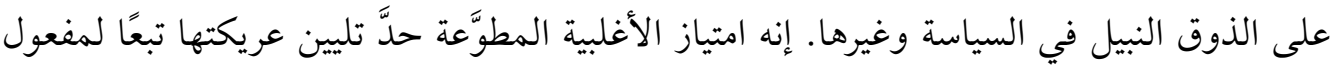

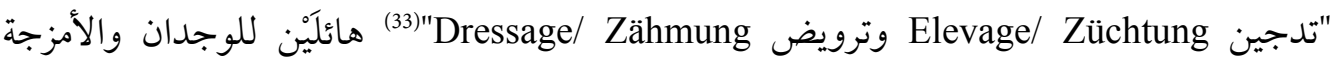
والأفكار. وفي الغالب يؤهل ذلك الامتياز كل تلك الأغلبية للعبث بالحياة السياسية في الانتخابات، وترون

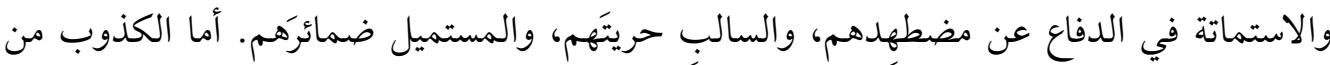

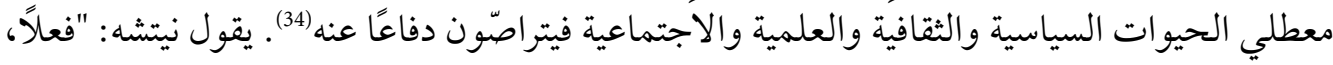

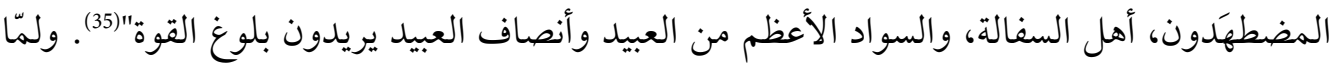

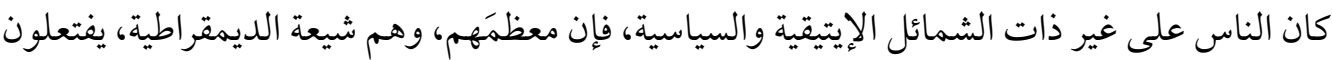
معادلة سياسية مقيتة، قوامُها أنّ التساوي في الحقوق هو العدالة عينها. والواقع أن قراءة نيتشه النقدية

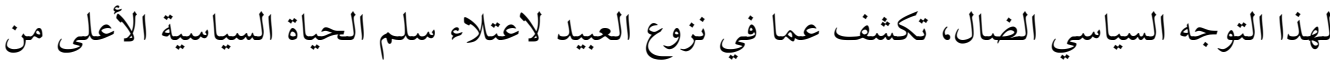
حقد على الأسياد؛ لأن "الحيف لا يكمن البتة في عدم تساوي الحقوق، بل في المطالبة بـ 'مساواة'

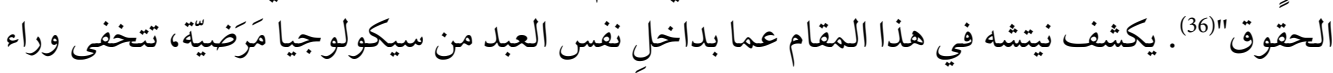

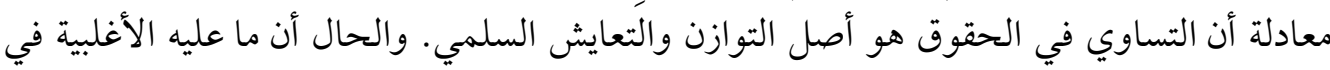
الديمقراطيات الليبرالية من عرجٍ وهلامية في تفكيرها السياسي يكفي لحبس أنفاس التئ السيد الأرستقراطي المهِيبِ بعظمة الرجال الكبار.

ثَمَّ، إذًا، مشاعر دونية يجههد أصحابها في افتراء نظام مفردات سياسية خبيثة ومغالطة؛ للاستيلاء على

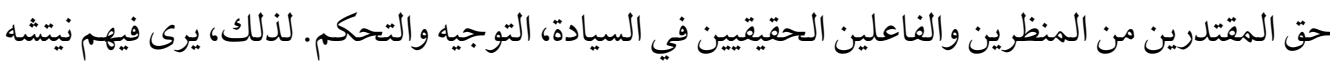

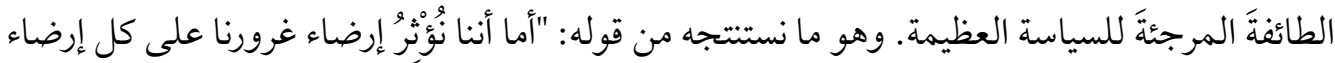

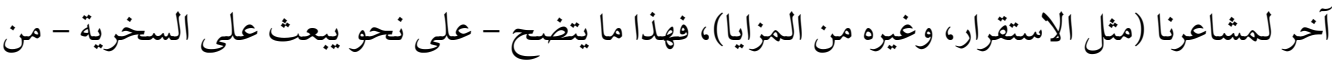

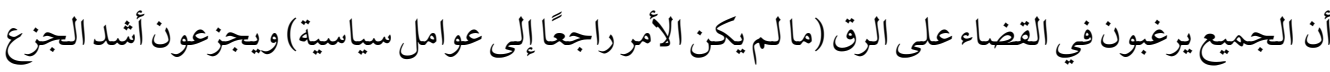

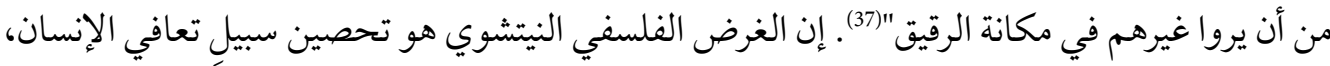

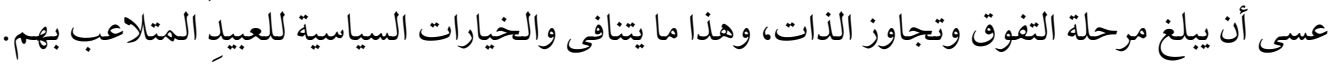

(32) Nietzsche, Ainsi parlait Zarathoustra, p. 151.

(33) Patrick Wotling, Le vocabulaire de Friedrich Nietzsche (Paris: Ellipses, 2007), p. 25.

(34) نذكّر بتعريبنا لمفهوم (Puissance/ Macht) في هذا المقام تحديدًا بالقوة وليس بالاقتدار؛ إذْ لا يُحمل هذا الأخير على العبيد كما هو بيّن في هذا السياق.

(35) Nietzsche, Fragments posthumes, vol. 13, p. 144.

(36) فريدريك نيتشه، نقيض المسيح: مقال اللعنة على المسيحية، ترجمة علي مصباح (بيروت/ بغداد: منشورات الجمل، 2011)،

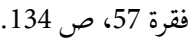

(37) Nietzsche, Humain, trop humain, § 457, p. 273. 
ومن فرطِ طَرِقِ الشعارات لعقولهم وتطويع أنفسهُم؛ يستحيلون إلى أهل نفاق أخلاقي وشقاق سياسي (38).

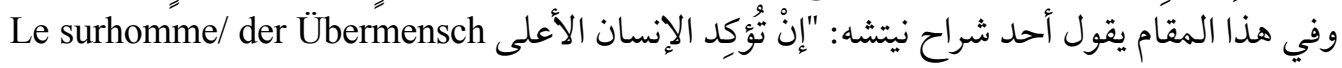
بوصفه هدفًا، هو أن تتعارض مع ضغينة الحينة القطيع، وليس فقط مع المسيحية، ولكن، أيضًا مع المساواة

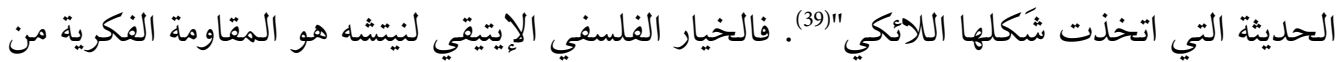
أجل إجلال الوجود و إعلاء شأن المعرفة المرحة die fröhliche Wissenschaft، والسياسة الكبرى (40). وشرط ذلك كله هو تعرية المقولة السياسية - الحقوقية: المساواة الليبرالية L'égalité libérale. فلا تجوز وجدوز

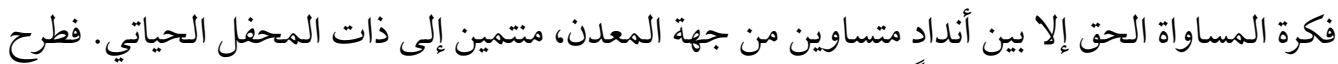

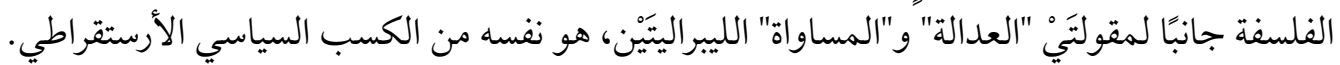

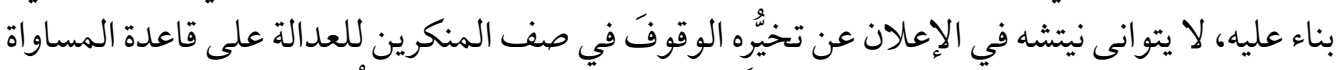

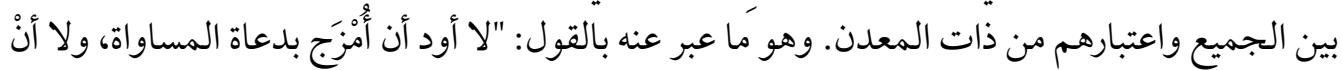

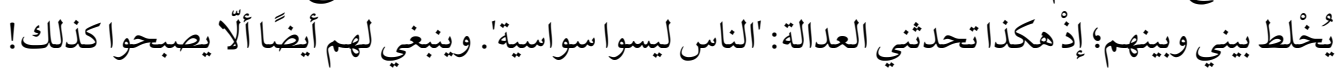

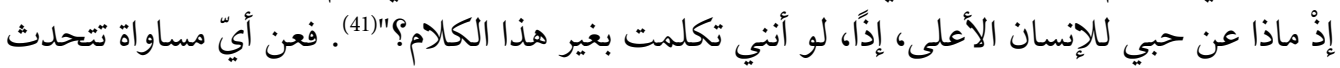

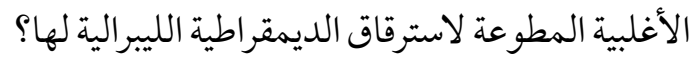

إنها المساواة النظرية في العيش أمام الدولة والتحكم في آليات تدابيرها للشأن العام من قِبَلِ

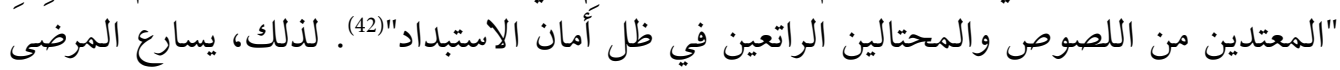

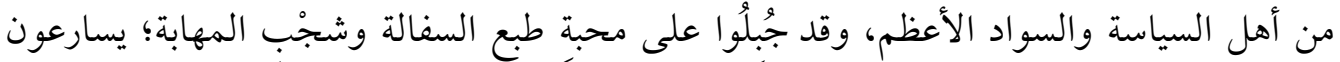

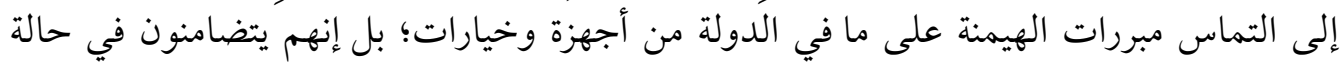

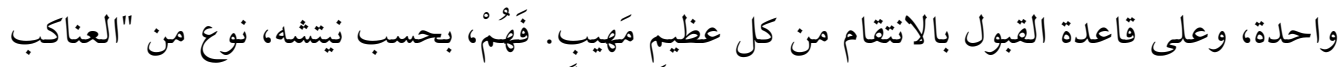

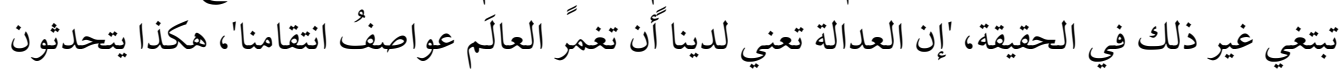

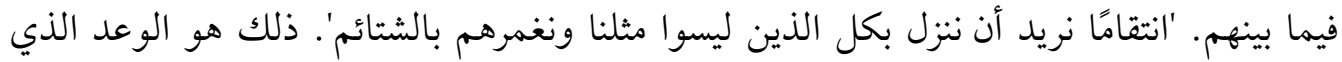
يأخذه ذوو قلوب العناكب على أنفسهم. 'إرادة المساواة؛ ذلك ما سيغدو من هنا فصاعدًا اسمًا

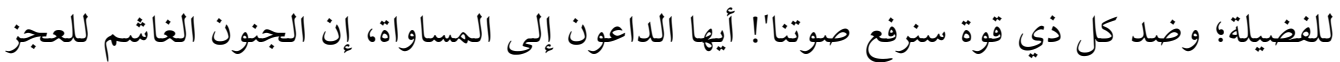

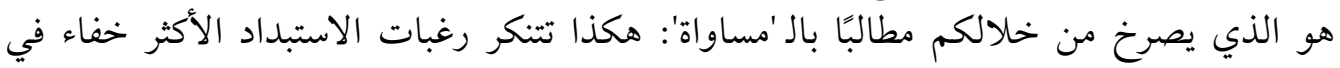

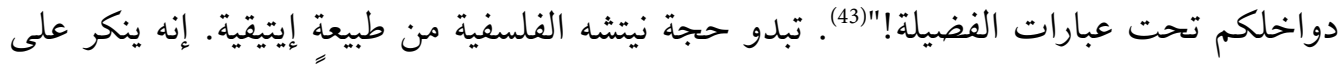

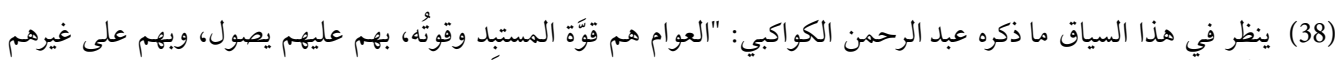

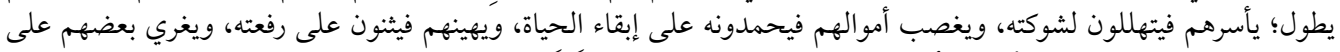

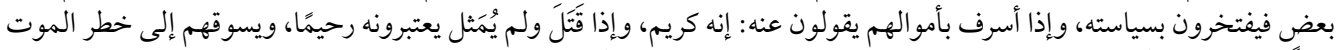

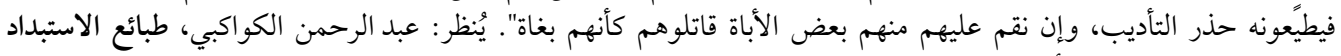

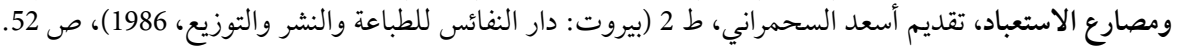

(39) Reboul, p. 134.

(40) Nietzsche, Fragments posthumes, vol. 14, p. 377.

$$
\text { نيتشه، هكذا تكلم زرادشت، ص 196-197. }
$$


مفسدي الحياة السياسية تزكيتهم صلف التوجه "الأخلاقوي" الذي باتت عليه العامة من الناس، وهم منقادون قطيعًا يتدبر أمره الساسة. هو ذا العمل بمقولات لات الخير والشر والالتزام بها. إنهم يستمتعون

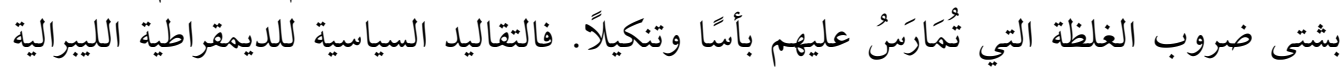

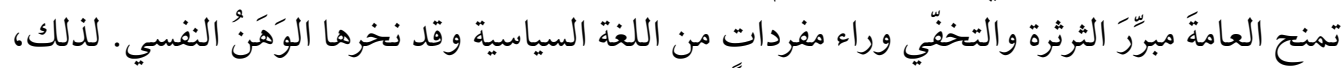

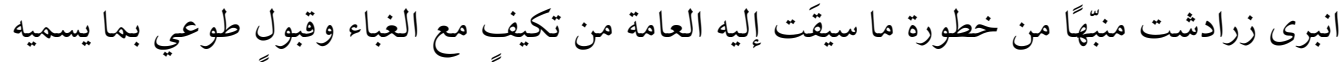

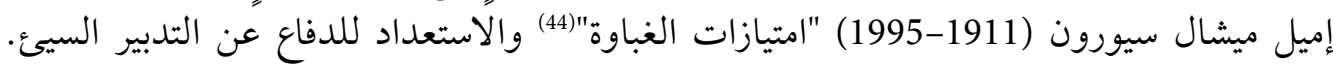
فترى العوام يرددون صنوف المقولات المتداوكلة، وخاصةً إذا نطق بها زعماء "الطبقات العليا"(45).

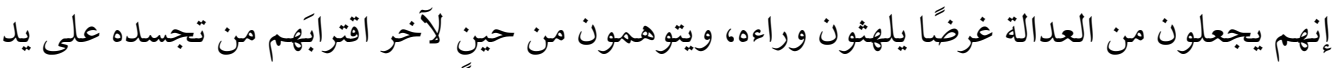

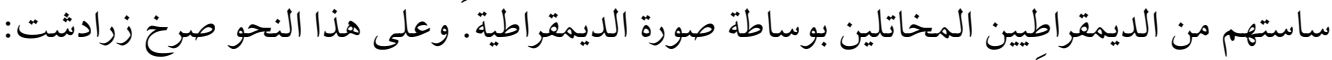

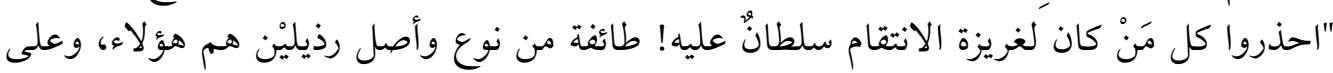

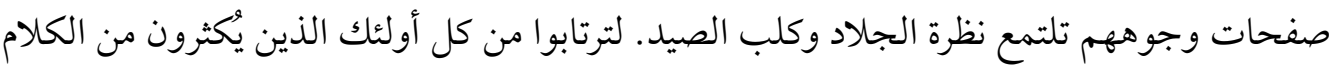

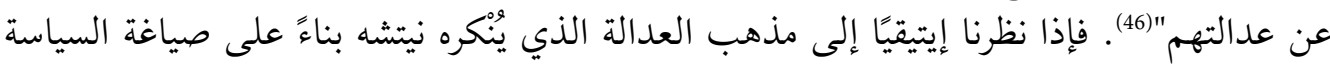

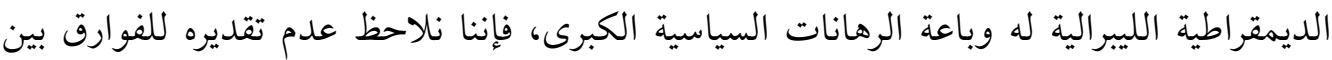

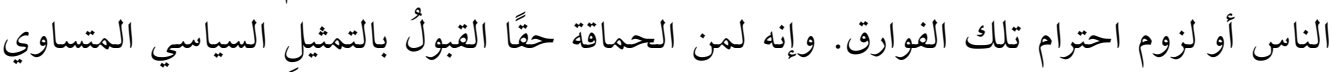

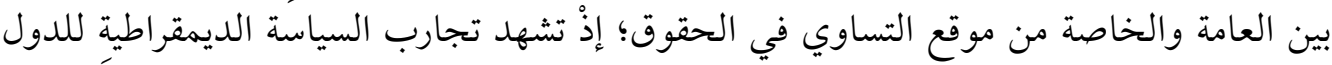
الحديثة منها والمعاصرة على يسر التحكم في وجدان العوام وتوجيهُهم الوجهة المرجوة من قِبَّلِ المتاجرين بمقولات الديمقراطية وتوابعها.

إن هم نيتشه هو المحافظة على خصوصية "الفوارق النوعية" البيّنة بين البهامة والمهابة. ولعلنا نجد،

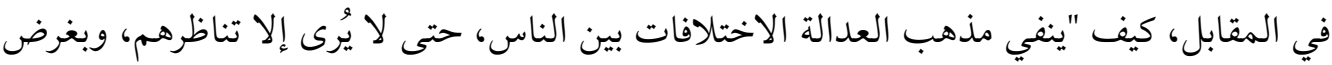

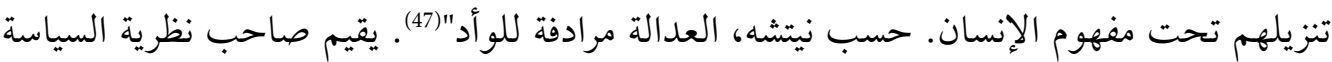

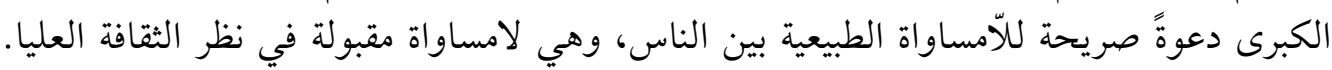

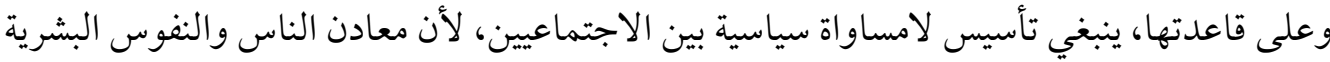
عمومًا قد أهلتها الطبيعة لإنجاز مهمات متفاوتة في الحياة، وهي على على مقدار التفاوت بينهم من جهية

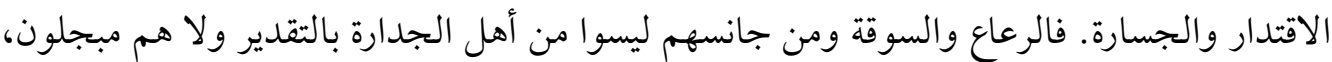

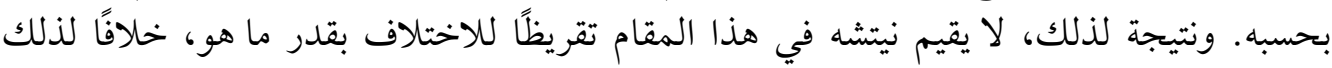

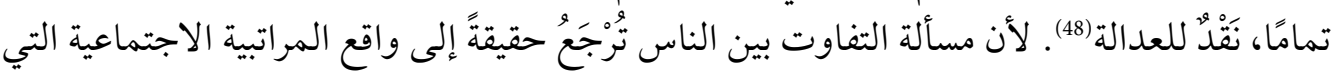

(44) Emil Michel Cioran, Précis de décomposition (Paris: Gallimard, 2007), p. 139.

$$
\text { ينظر تفصيل نيتشويٌ للمسألة في: }
$$

Friedrich Nietzsche, Fragments posthumes: Été 1869-Printemps 1872, Michel Haar, Philippe Lacoue-Labarthe \& JeanLuc Nancy (trad.), Euvres philosophiques complètes, vol. 1 (Paris: Gallimard, 2008), § 7, pp. 430-431.

$$
\text { نيتشه، هكذا تكلم زرادشت، ص } 196 .
$$

(47) Gisèle Souchon, Nietzsche: Généalogie de l'individu (Paris: L'Harmattan, 2003), p. 19.

(48) Ibid., p. 21. 


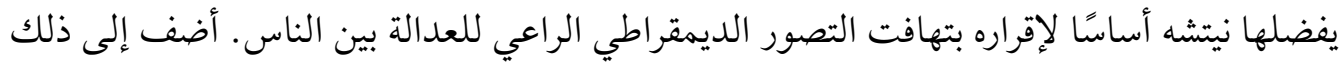

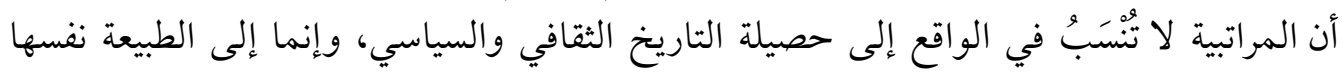

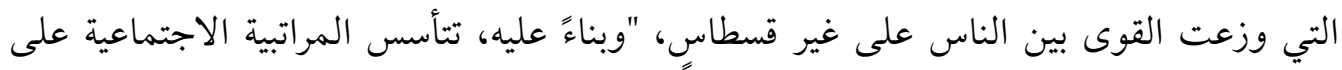

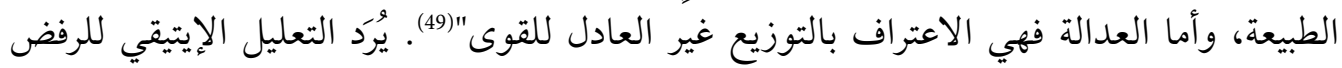

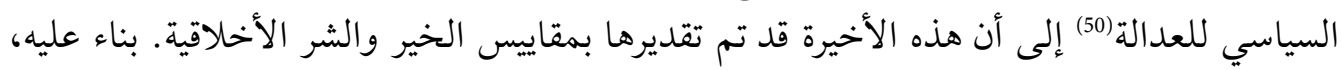

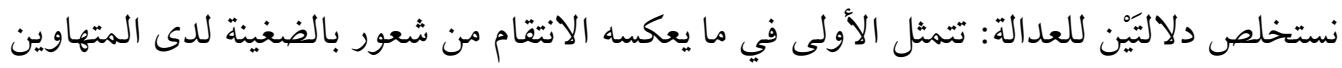

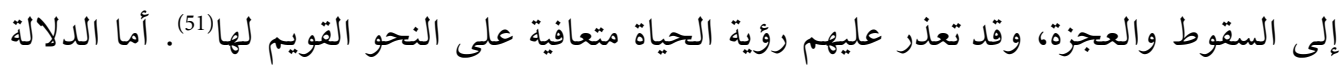

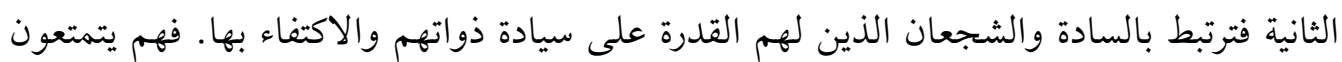

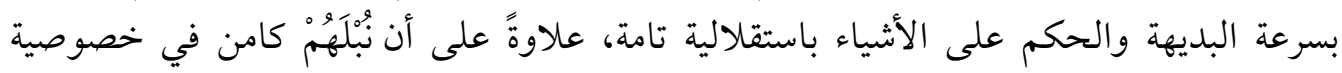

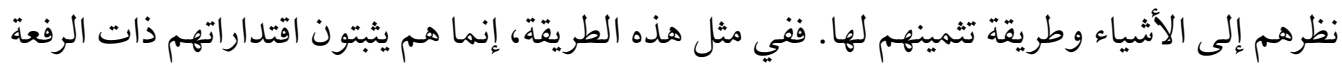

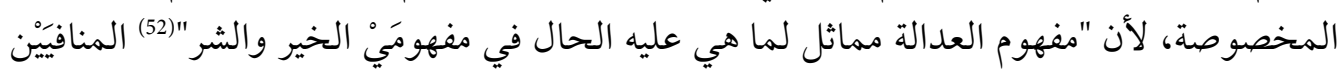

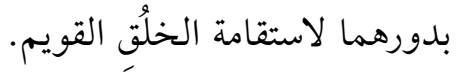

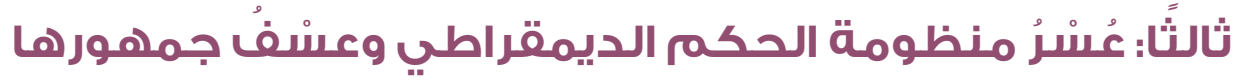
"إن نشاط الفيلسوف لا يلفت أبدًا إليه انتباه "الجمهور"، ولا ينتزع له تأييد الجماهير أو حماسة

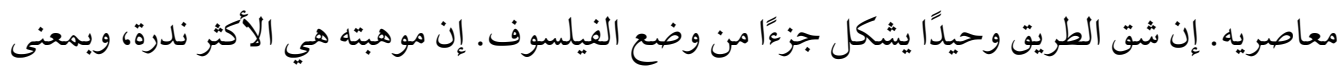

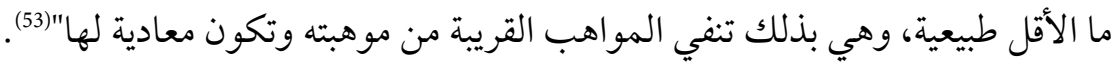

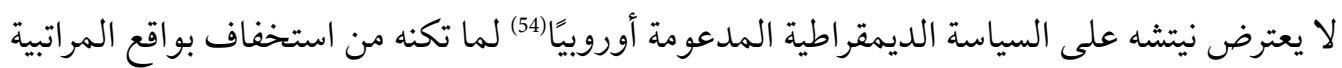

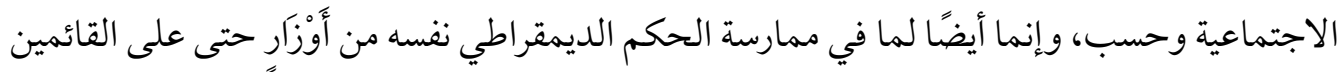

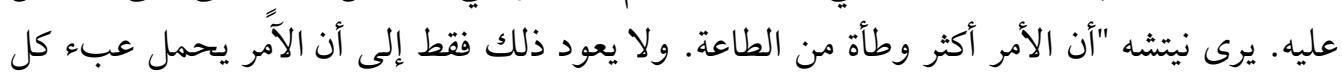

(49) Clair, p. 140.

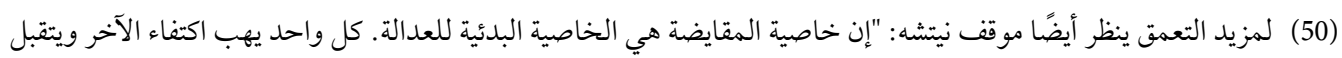

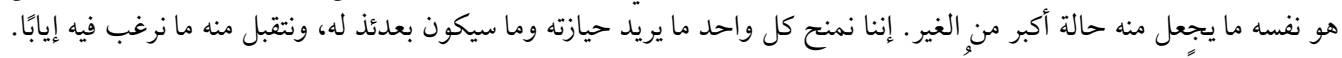

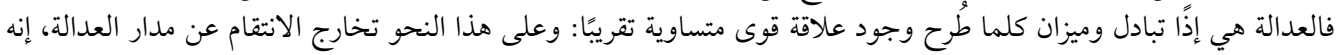

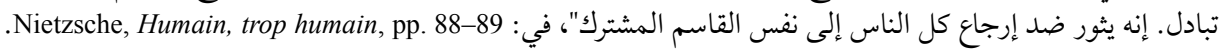

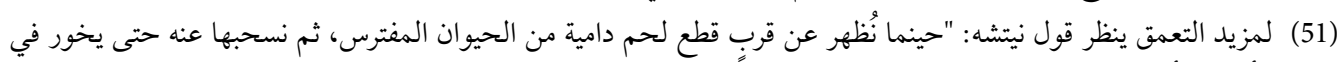

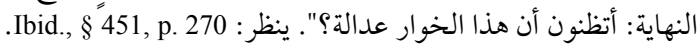

(52) Clair, p. 142.

(53) فريدريك نيتشه، الفلسفة في العصر المأساوي الإغريقي، ترجمة سهيل القش، تقديم ميشال فوكو (بيروت: المؤسسة الجامعية

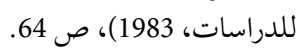

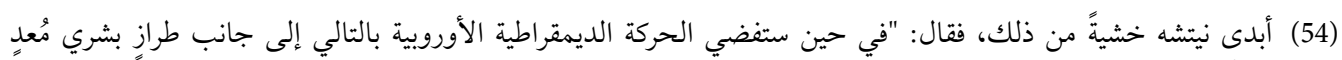

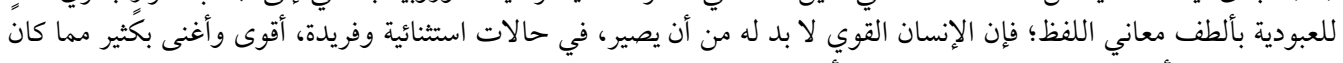

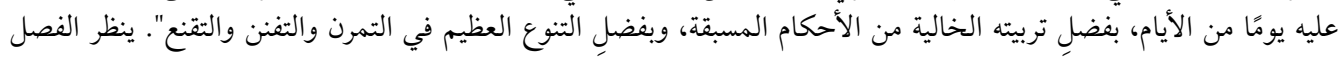

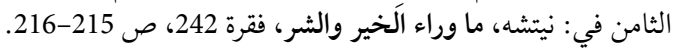


المطيعين، وأن ذلك العبء يسحقه بسهولة"(55). لكنْ ما الوهن الذي نال من الحاكمين بالديمقراطية،

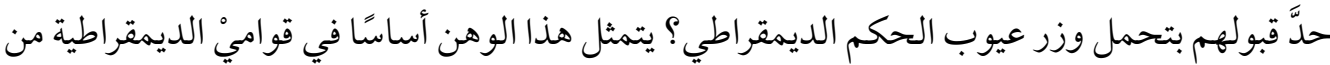
منظورية فلسفة نيتشه السياسية، وهما: أولاًا: انحطاط من أصلٍ كنسي (56) برر، من الجهة الأخلاقوية Moralisme، الدعاية للديمقراطية الهادفة إلى تأبيد الطغيان(57)

ثانيًا: انحطاط من أصلٍ أخلاقي تمثل، من الجهة السيكوفيزيولوجية Psycho-physiologique، في

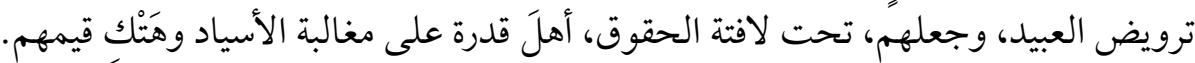
وكيفما كان الأمر، "لا تكون الأغلبية في السياسات الديمقراطية (58) إلا ضاغطةً ضَغْط المستبدين

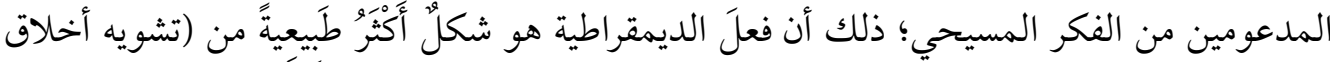

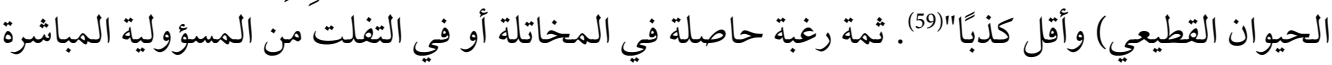
عما يهدد الكيان المجتمعي برمته في تبني الدول الحديثة والمعاصرة للنظام السياسي الديمقراطي.

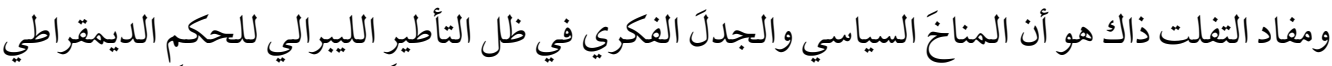

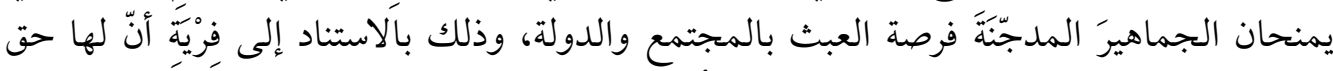

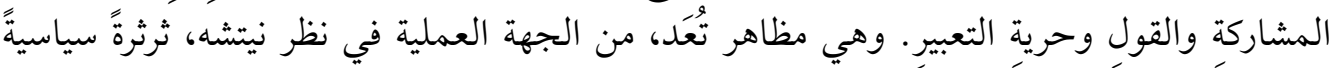

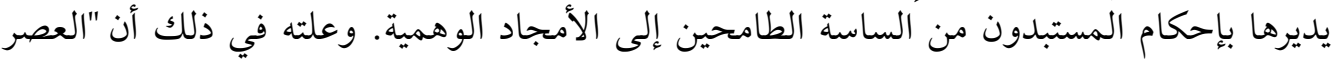

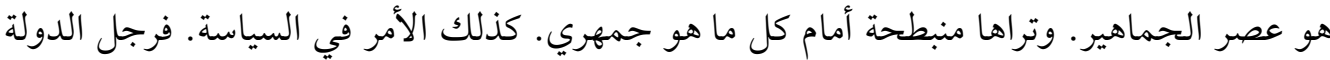

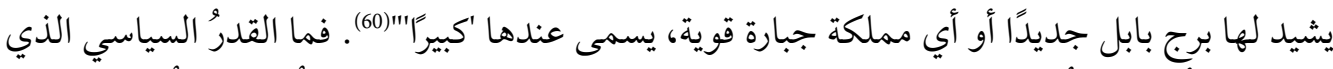

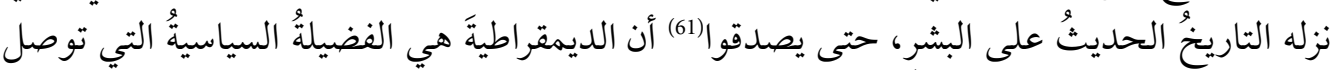

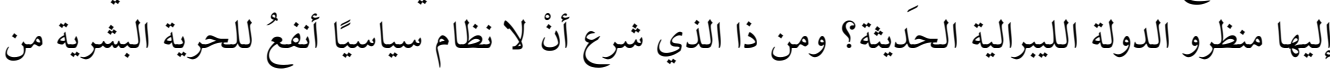
الديمقر اطية؟

$$
\text { نيتشه، هكذا تكلم زرادشت، ص } 226 .
$$

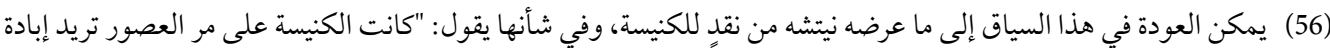

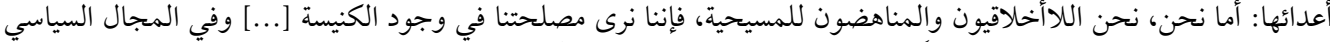

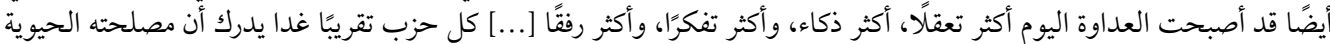

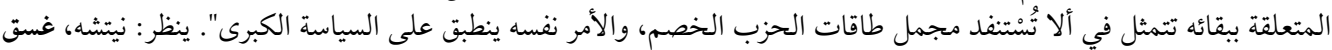

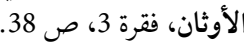

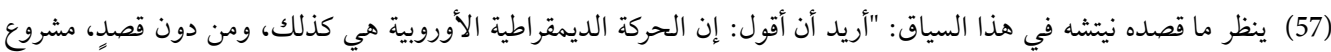

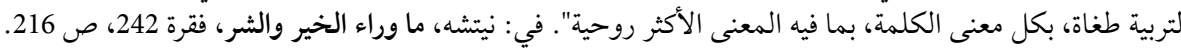

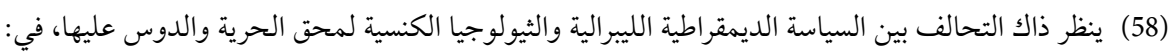
Nietzsche, Crépuscule des Idoles, § 38-39, pp. 133-135.

(59) Nietzsche, Fragments posthumes, vol. 13, p. 144.

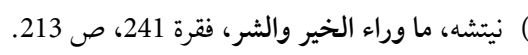

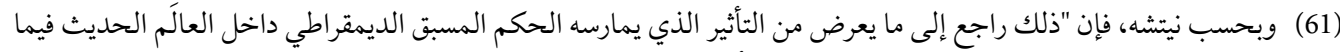

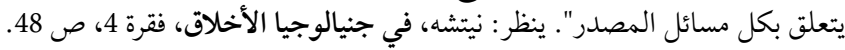


لا تزال الديمقراطية تمثل قَدَرًا نهائيًا غير قابل للرد السياسي، خاصةً إذا استغفلتنا أقنعتها الليبرالية وآلياتها

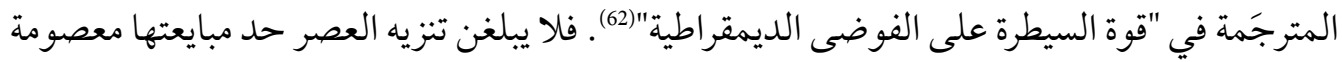

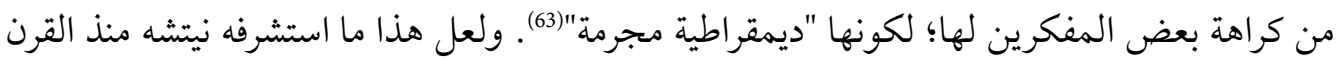

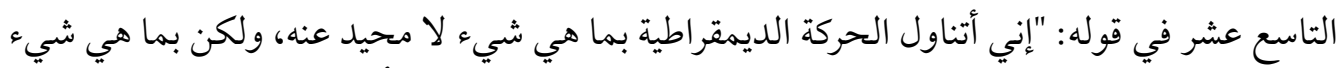

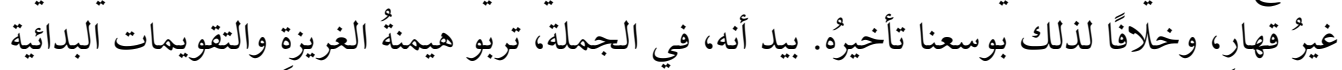

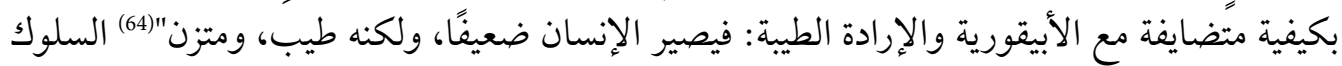

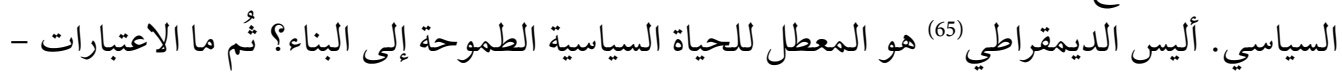

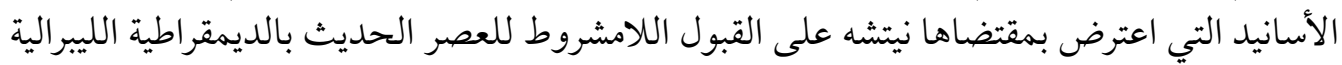

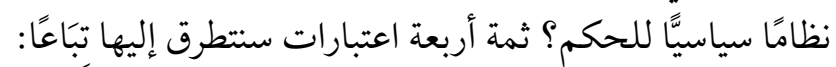

• الاعتبار الأول: تثبيتُ أخلاقِ الانحطاطِ عبر "الأحكام الديمقراطية المسبقة" (66). ولمّا كانت

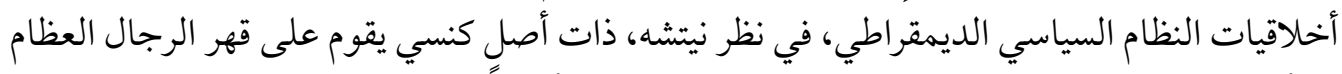

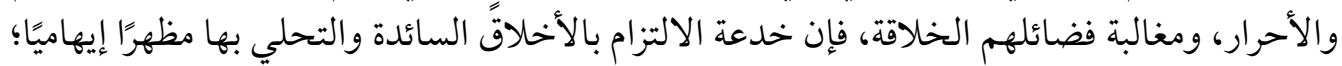

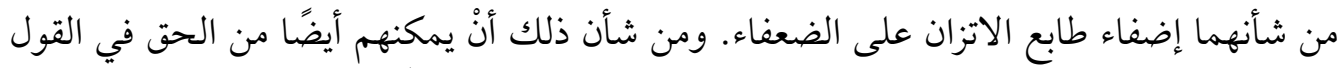

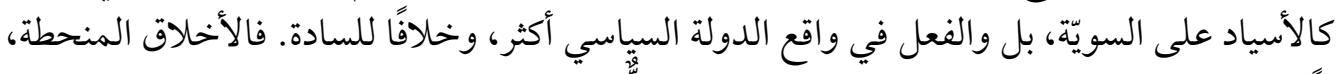

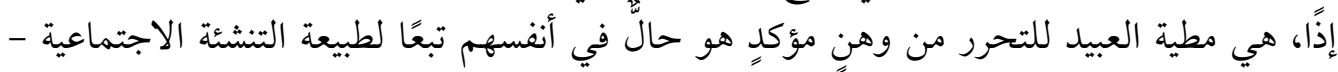

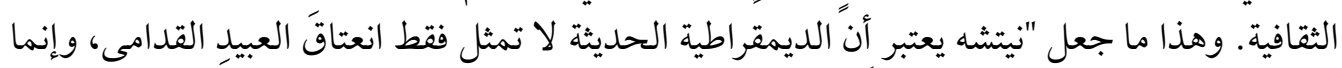

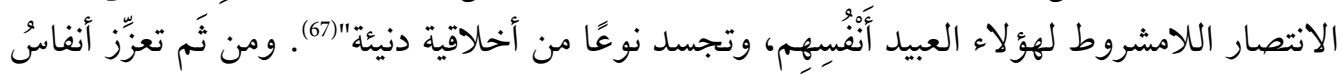

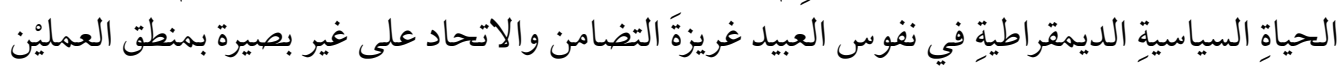

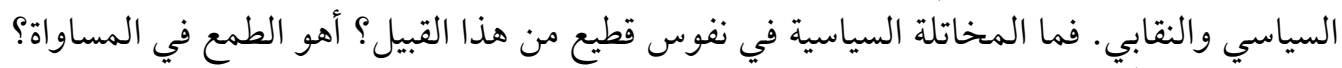

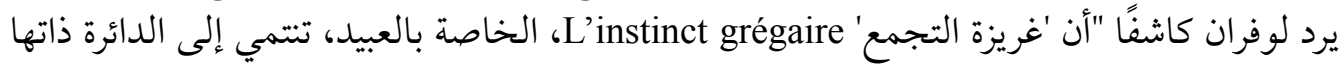
من 'إرادة المساواة' التي هي شكل معقلن من المثالِ الديمقراطي" '(68).

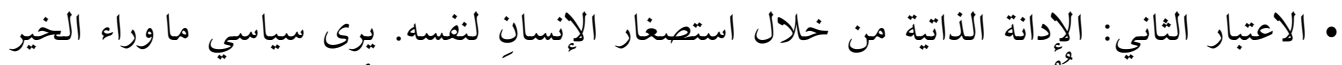

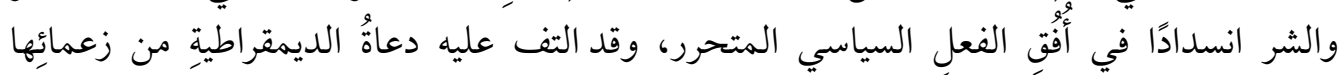

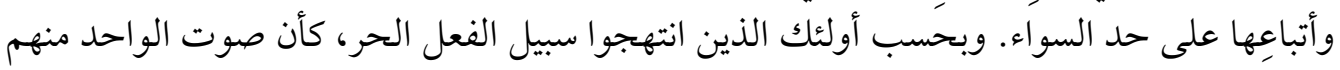

$$
\text { (62) جاك رانسيير، كراهية الديمقراطية، ترجمة أحمد حسان (بيروت: دار التنوير للطباعة والنشر والتوزيع، 2012)، ص } 16 .
$$

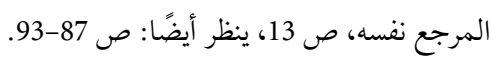

(64) Nietzsche, Fragments posthumes, vol. 11, p. 185.

$$
\text { كمكن الرجوع إلى قول نيتشه: "الديمقراطيون الأربعة الكبار: سقراط وعيسى المسيح ولوثر وروسو". يُنظر: }
$$

Nietzsche, Fragments posthumes, vol. 13, p. 26.

(66) Paul Valadier, Nietzsche: Cruauté et noblesse du droit (Paris: Michalon, 1998), p. 13.

(67) فرانسيس فوكوياما، نهاية التاريخ والإنسان الأخير، ترجمة فؤاد شاهين، جميل قاسم ورضا الشايبي (بيروت: مركز الإنماء القومي، 1993)، ص فرانسيس فوكاما، 32.

(68) Lefranc, p. 126. 
يقول: "نحن الذين نتمي إلى إيمانٍ آخر، نحن الذين لانأخذ الحركة الديمقراطية بوصفها طورًا

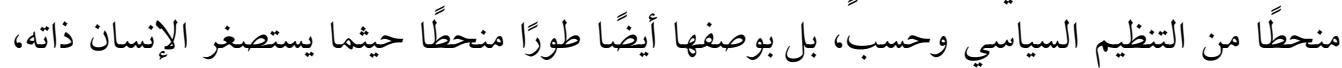

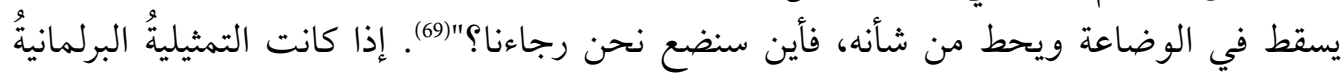
La représentation parlementaire

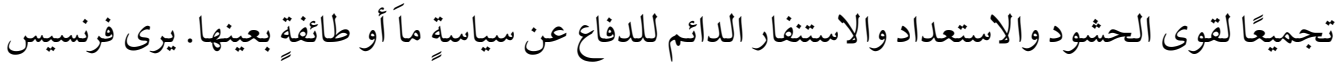

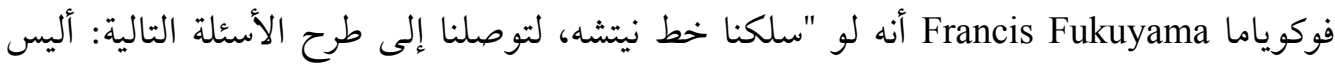

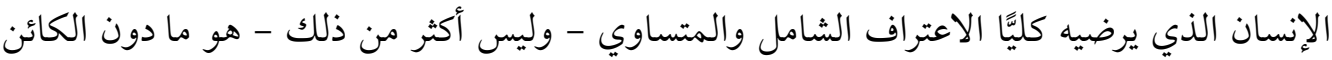

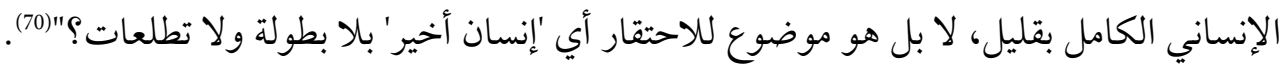

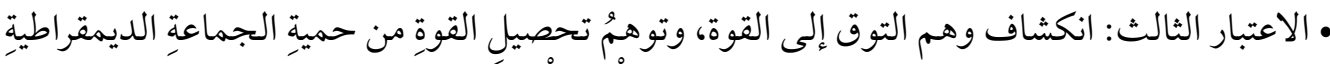

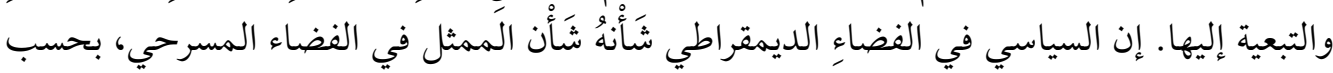

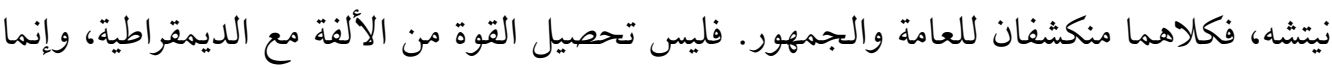

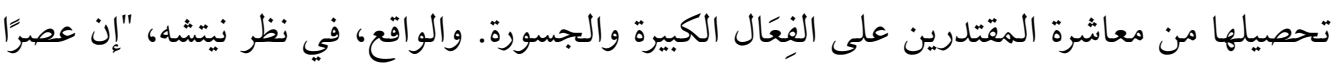

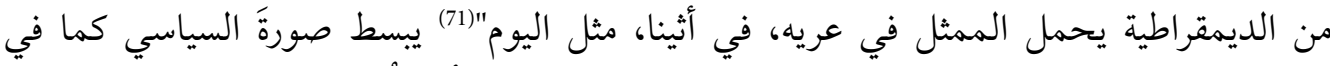

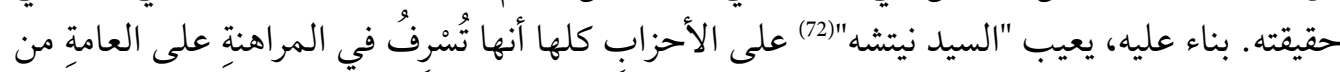

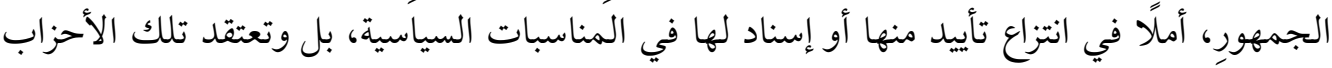

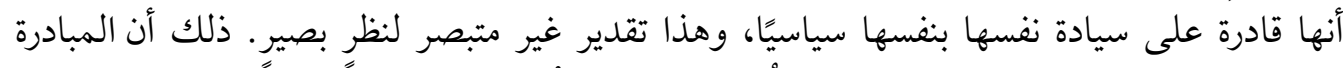

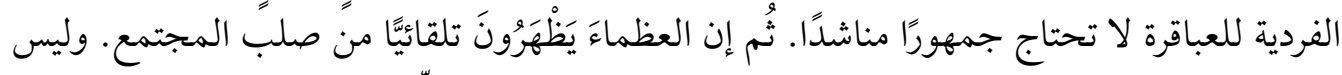

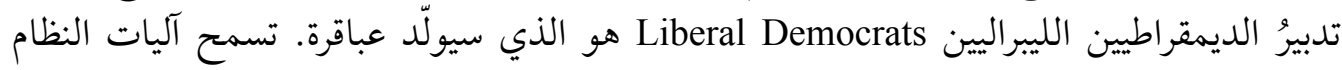

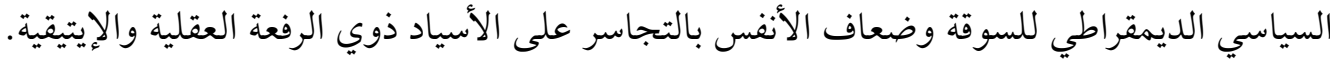

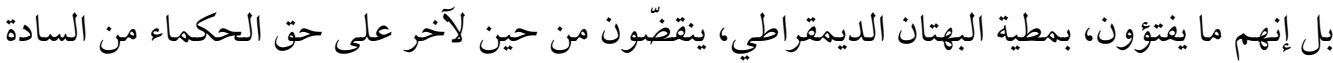

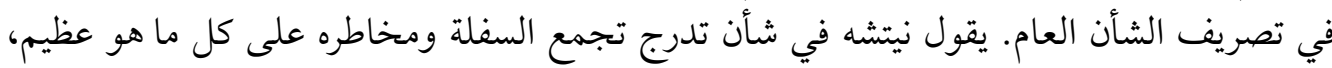

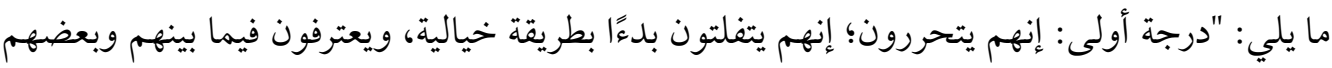

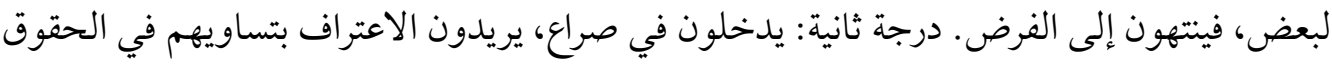

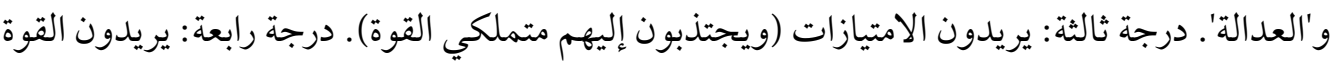

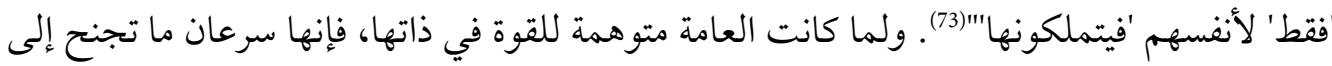

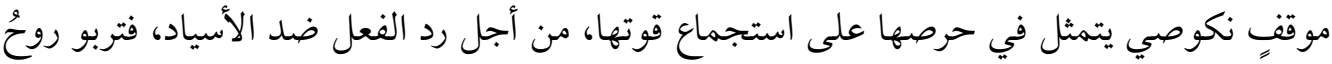

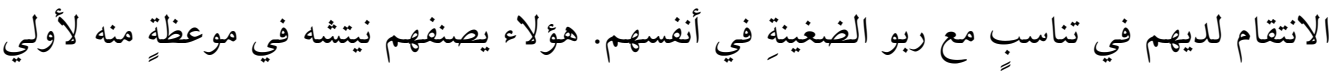

(69) Friedrich Nietzsche, Par-delà bien et mal: Prélude d'une philosophie de l'avenir, Cornélius Heim, Isabelle Hildenbrand \& Jean Gratien (trad.), Euvres philosophiques complètes, vol. 7 (Paris: Gallimard, 2006), § 203, p. 116.

(71) Nietzsche, Fragments posthumes, vol. 11, p. 181.

$$
\text { تسمية أطلقها نيتشه على نفسه. يُنظر : نيتشه، العلم الجذل، فقرة 2، ص } 7 .
$$

(73) Nietzsche, Fragments posthumes, vol. 11, p. 144. 
العزم في الأمرِ السياسي بالقول: "في كل أنّّ من شكواهم يرن صوت الانتقام، وفي كل مديح من

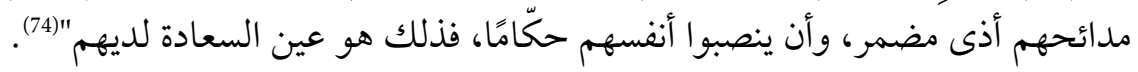

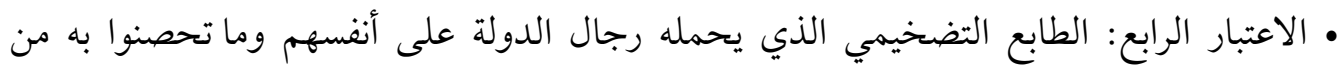

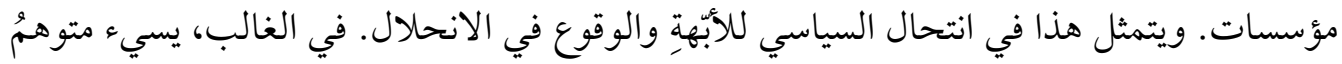

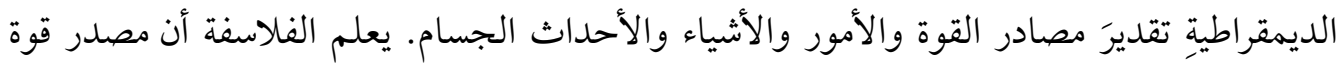

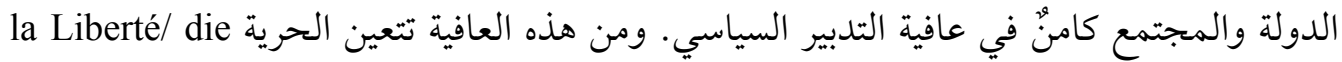

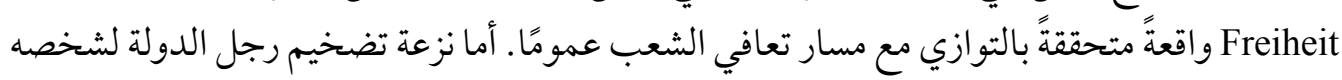

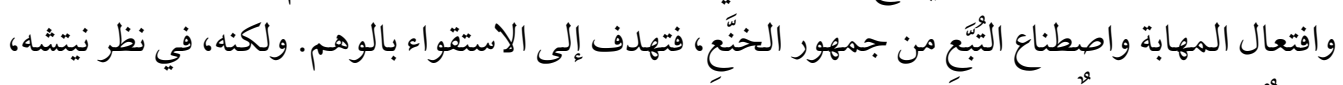

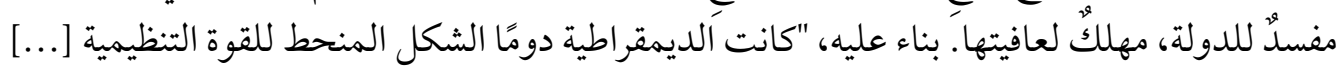

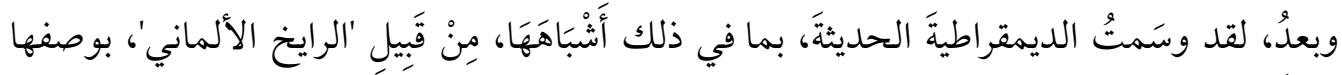

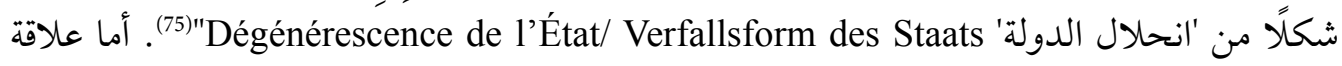

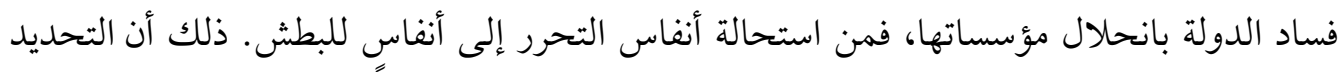

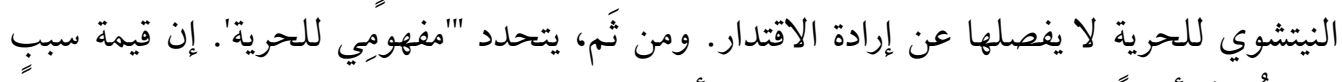

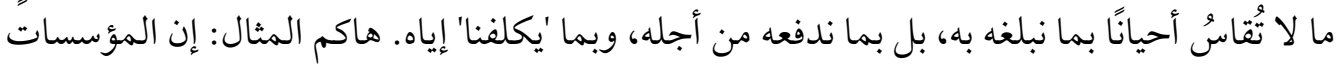

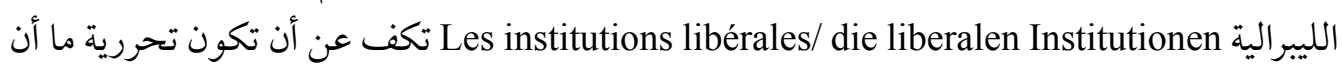
تتمكن: وإضافة إلى ذلك، لا شيء منذر بنسف الحرية نسقيًا غير المؤسسات الليبرالية"(76).

\section{رابعَّا: الحق الأرستقراطي في الاعترافِ بـالفرق

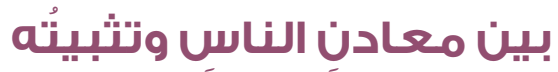

"لماذا هو شديد الإباء؟ يتميز الطبع النبيل من الطبع الفظ بكونه لا يتوفر مثله على عدد من العادات

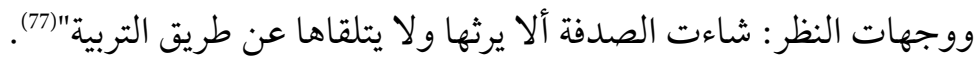

لماذا أعلنت الفلسفة السياسية النيتشوية عن أفكارها القائمة "ضد مذهب المساواة"(78) بين كل الناس؟

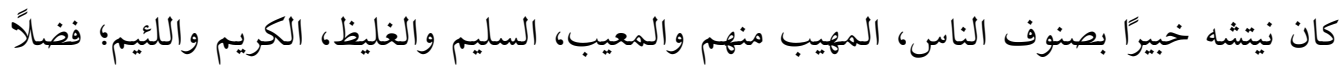

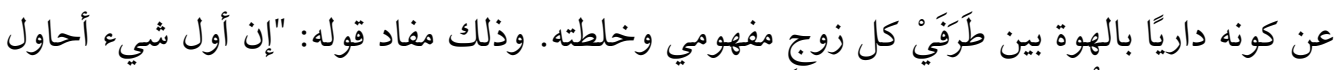

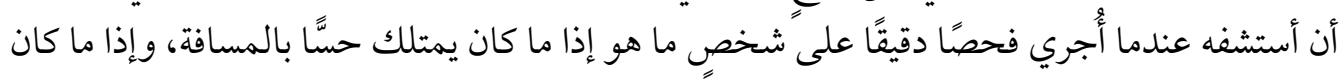

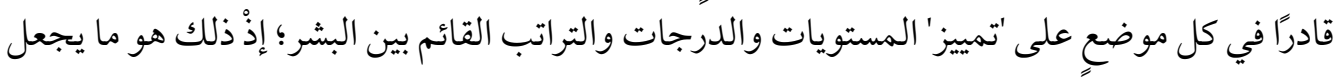
نيتشه، هكذا تكلم زرادشت، ص 195.

(75) Nietzsche, Crépuscule des Idoles, § 39, p. 134.

(76) Ibid., § 39, p. 133.

(78) Valadier, p. 70. 
منه رجلاً شريفًا Gentilhomme"(79). فمن المنظورية المراتبية، يرى نيتشه أن المواقع الاجتماعية في

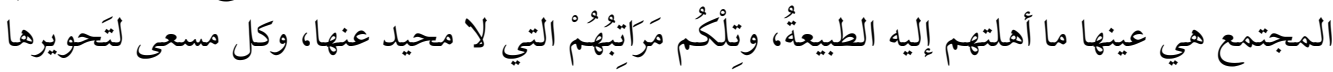

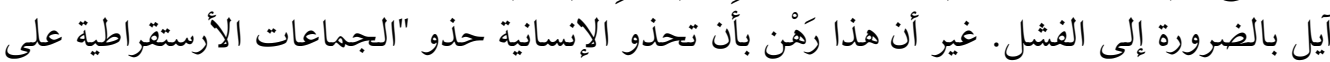

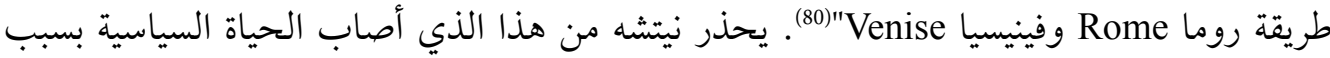
من أنفاس الفكر الكنسي؛ لكونه يمثل خطرًا على شعور عظماء رجال الأرستقراطية بالمسافات تجاه

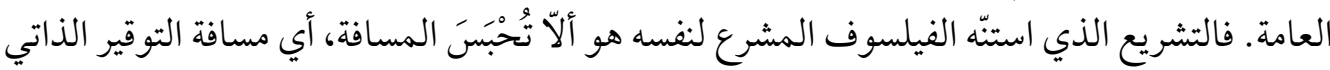
التي للأرستقراطي (81). فالكنيسة تهاب ما في نفوس الكبار من شجاعة واقتدار وإقدام على الجسيم

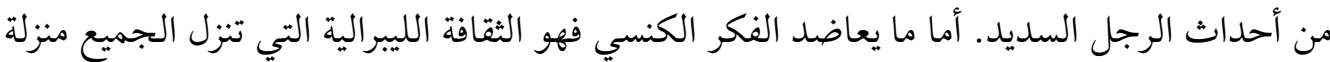
الكل المتساوي، وهو ما يتنافى وأنفاس الحس الأرستقراطي. فمجمل الأفكار الثيولوجية للمؤسسة

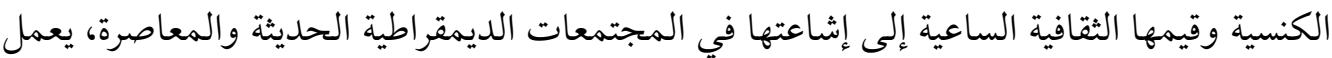

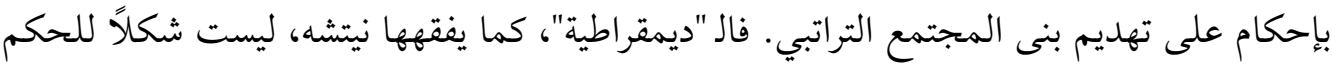

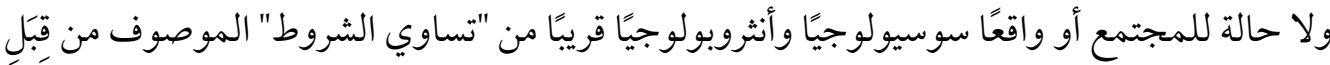

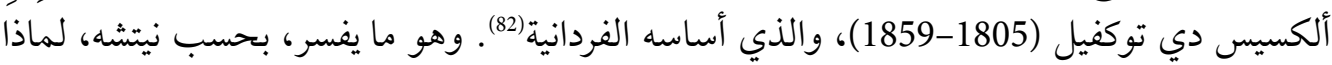

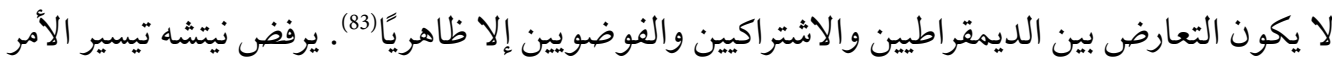
السياسي على باعة الهبات الديمقراطية كلما تحصنوا بسند من ثقافة الكنيسة. وفي ذلك ذين ينبه قائلاً:

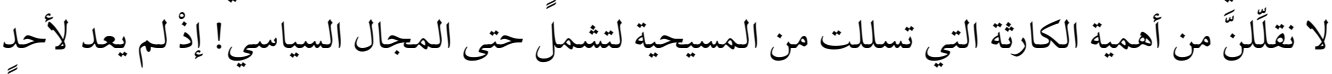
في يومنا هذا من شجاعة على المطالبة بحقوق امتيازية وبحقوق السيادة، وعلى فرض مشيه مشاعر الاحترام

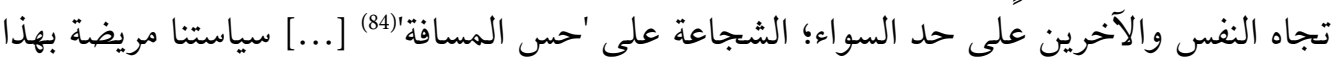
الافتقار إلى الشجاعة!"(85).

ثمة جانب آخر وهو الثروة التي في إمكانها تثبيت الطموح الأرستقراطي للإبقاء على مسافة التفاوت،

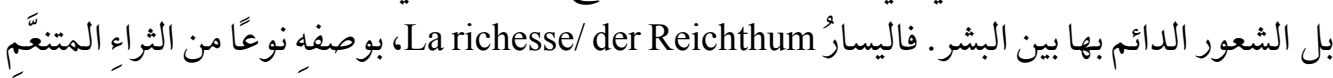

$$
\text { فريدريك نيتشه، هذا هو الإنسان، ترجمة علي مصباح (كولونيا: منشورات الجمل، 2003)، فقرة 4، ص } 148 .
$$

(80) Nietzsche, Crépuscule des Idoles, § 38, p. 134.

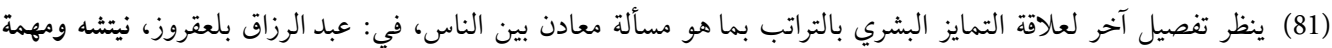

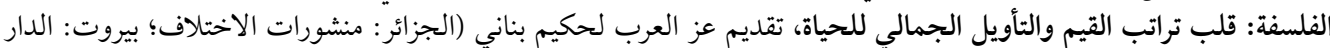

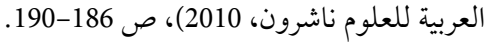

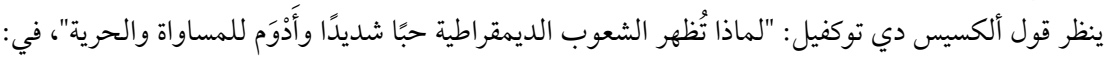

Alexis de Tocqueville, De la Démocratie en Amérique Collection: Bouquins (Paris: Robert Laffont, 1986), p. 493.

(83) Brigitte Krulic, "Nietzsche et la critique de la modernité démocratique," Archives de Philosophie: Recherches et Documentation, vol. 64, no. 2 (2001), p. 311.

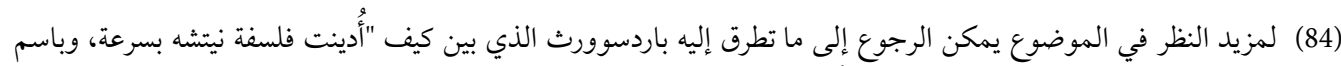

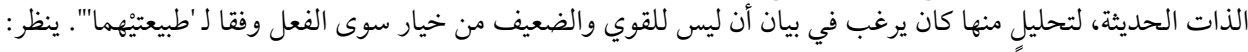
Richard Beardsworth, Nietzsche (Paris: Les belles lettres, 1997), p. 34

$$
\text { نيتشه، نقيض المسيح، فقرة 43، ص } 96 .
$$




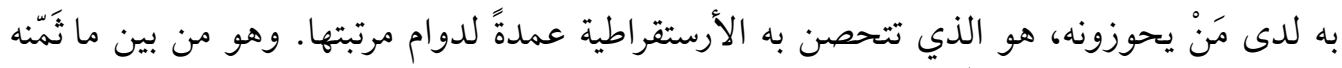

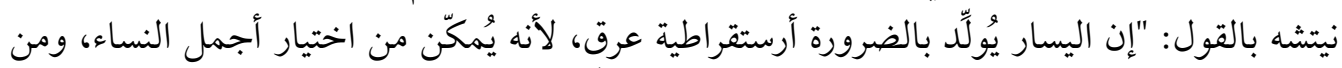

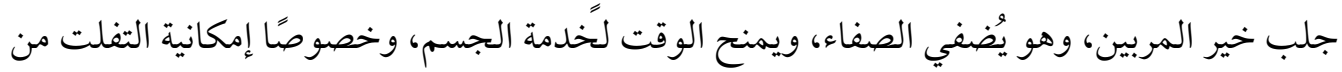

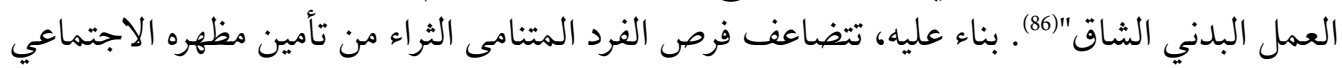

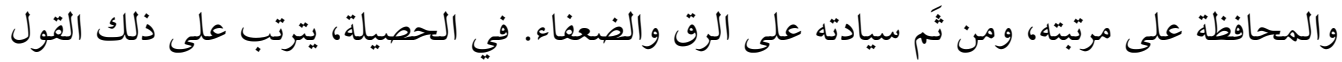

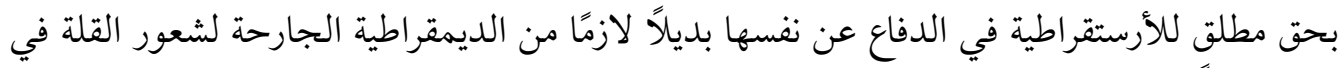

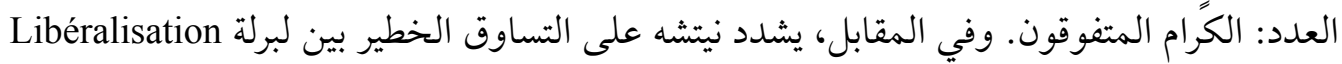

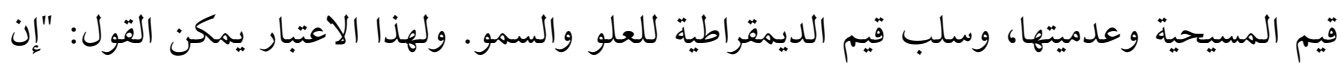

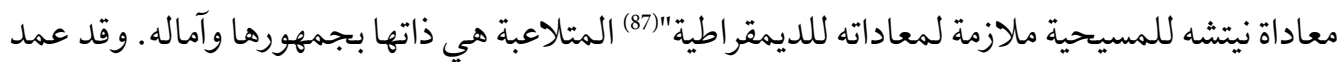

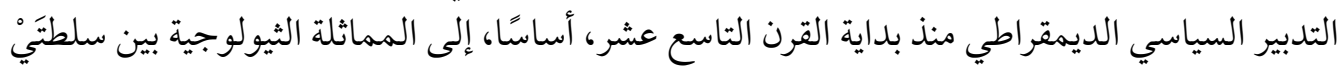

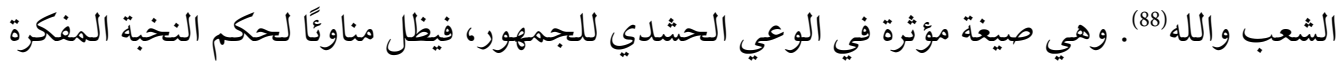

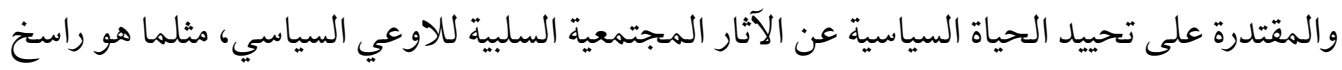
في أنفس العوام المهيئين بطبعهم للوقوع في المخاتلة الذكية لليبراليين.

\section{خامسًا: فلسفة نيتشه والحق الفلسفي في الدفّاع عن السياسة الأرستقرّاطية}

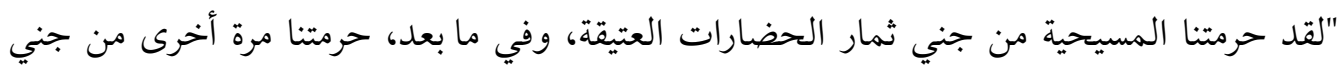

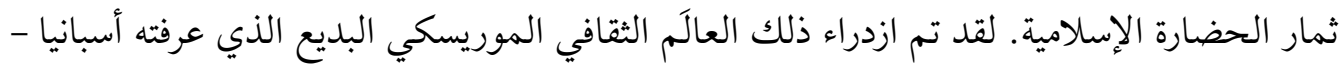

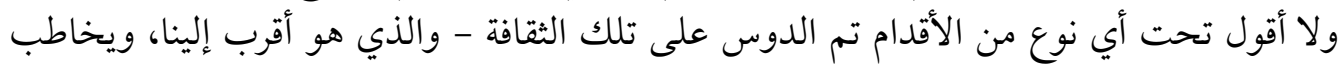

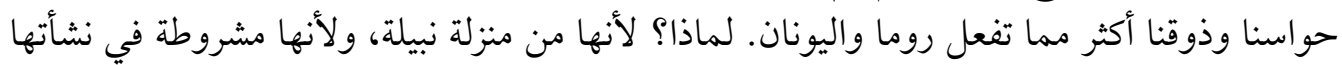
بغرائز فحولية، ولأنها تقول: نعم للحياة، مع زيادة في الرهافة النادرة لبدائع الحياة الموريسكية" (89). لا يمثل نقد نيتشه للديمقراطية ضربًا من الطوباوية أو الهدم العبثي، وإنما هو في الواقع طرح

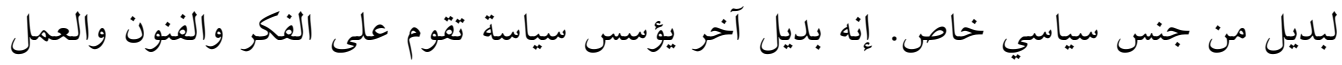

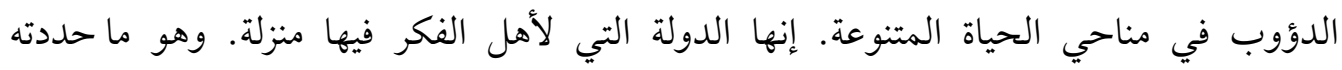

(86) Nietzsche, Humain, trop humain, § 479, p. 288.

(87) Brigitte Krulic, Nietzsche penseur de la hiérarchie: Pour une lecture tocquevillienne"de Nietzsche, Collection: Ouverture philosophique (Paris: L'Harmattan, 2002), p. 117.

(88) يمكن الرجوع إلى هذه الفقرة المنتزعة للألماني كارل شميت Carl Schmitt (1888-1985): "يبقى صحيحًا أن الآثار اللاحقة

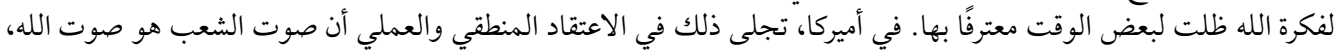

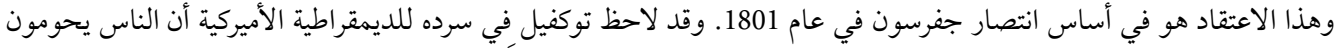

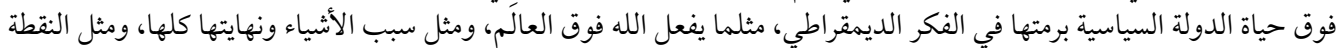

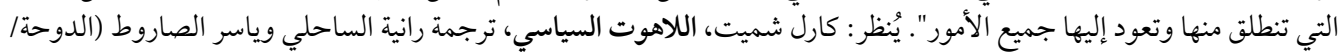

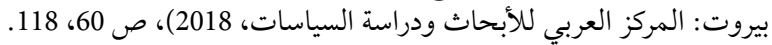
نيتشه، نقيض المسيح، فقرة 60، ص 142. 
أنجيل كريمر - ماريتي (1927-2013) في قولها: "تبدو دولة نيتشه، إذًا، قبل كل شيء، دولة الثقافة،

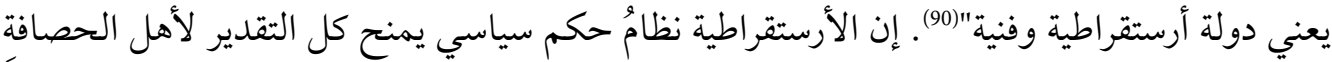

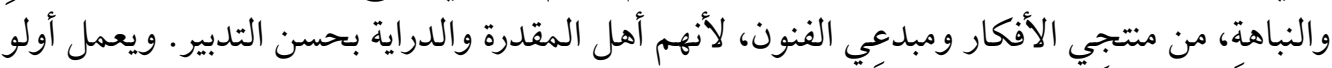

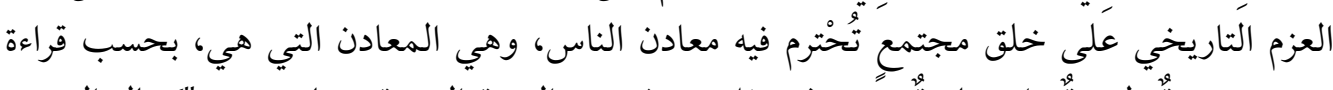

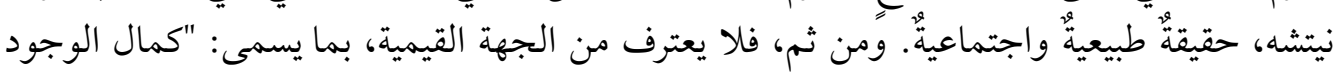

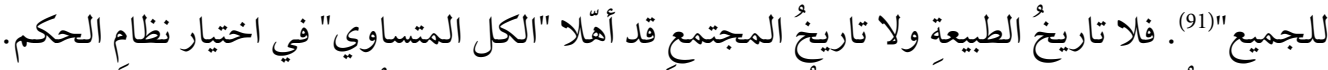

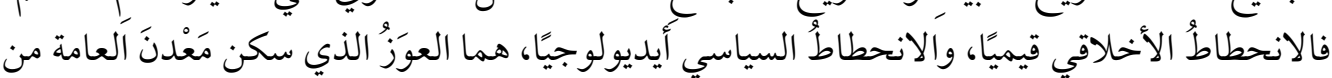

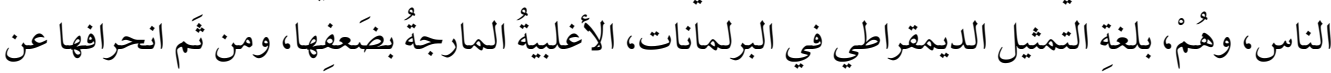

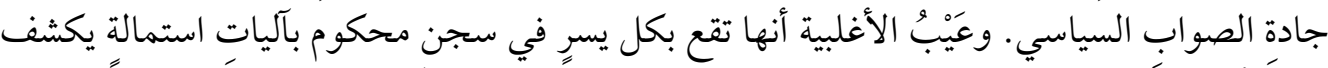

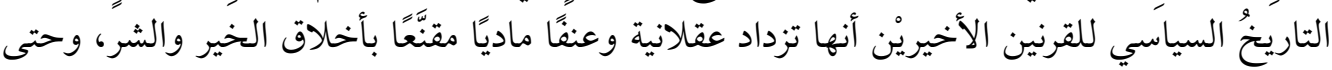

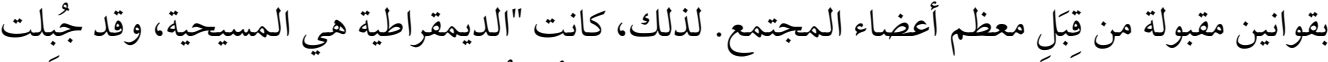

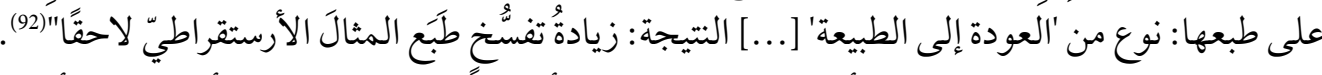

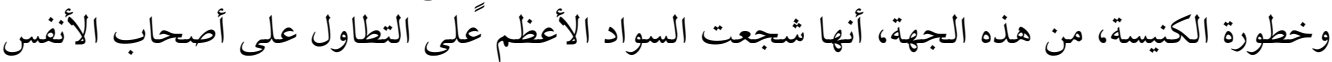

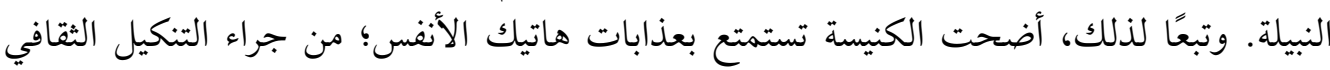

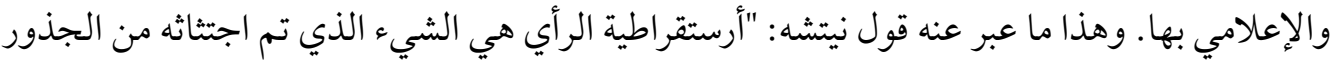

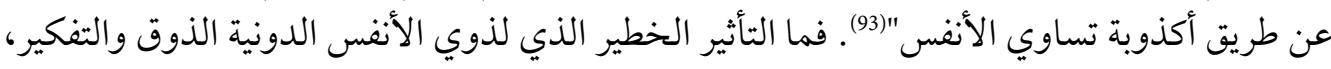

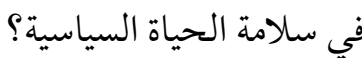

إنها الخطورة المتمثلة في قبولهم بالدناءة التي دفعهم إليها، وعن طيب خاطر، المستبدون المتملكون

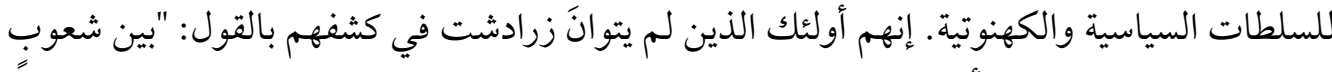
ذات لسان غريبٍ، عشت بأذنين مسدودتين كي تظل بعيدة عن مسمعي سمسرتهم ومساوماتهم على إنى

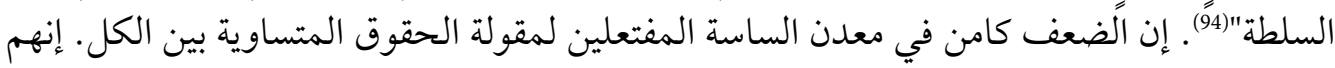

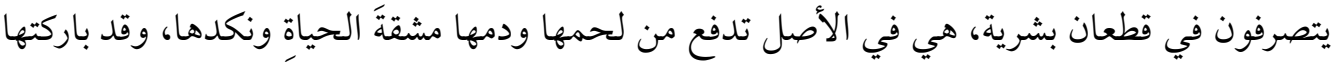

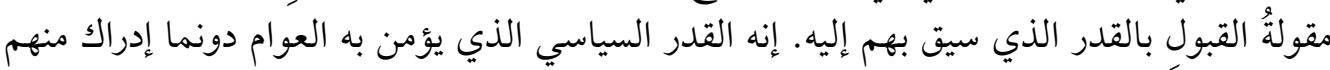

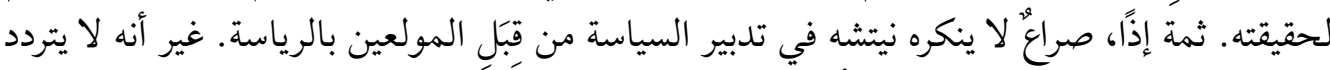

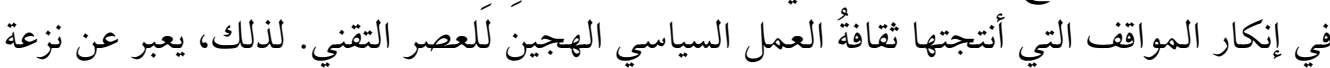

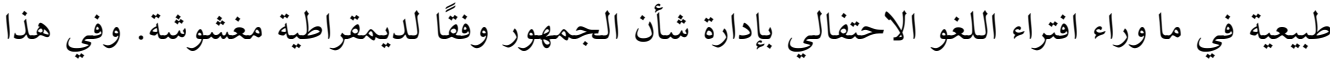
السياق، يقول نيتشه: "موقفنا أكثر طبيعية في السياسات In politics: إننا نرى هـئا مشاكل القوة،

(90) Angèle Kremer-Marietti, Thèmes et structures dans l'œuvre de Nietzsche (Paris: Les cahiers des lettres modernes, 1957), p. 74.

$$
\text { ستيبان أوديف، على دروب زرادشت، ترجمة فؤاد أيوب (دمشق: دار دمشق، 1983)، ص } 69 .
$$

(92) Nietzsche, Fragments posthumes, vol. 13, p. 145.

$$
\text { نيتشه، هكذا تكلم زرادشت، نقيض، ص فقرة 190، } 190 .
$$




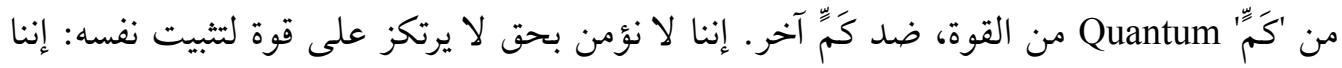

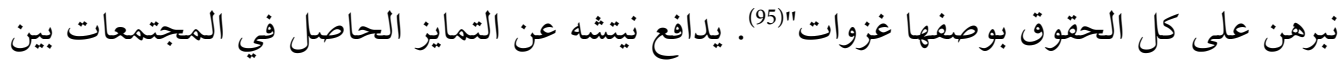

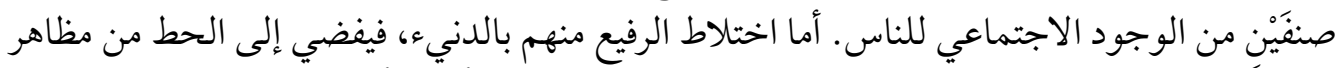

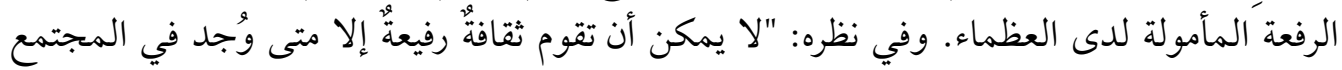

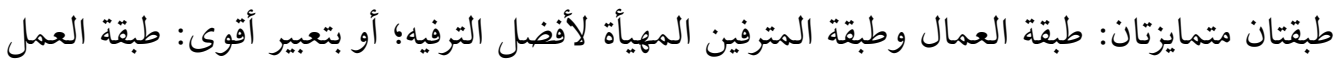

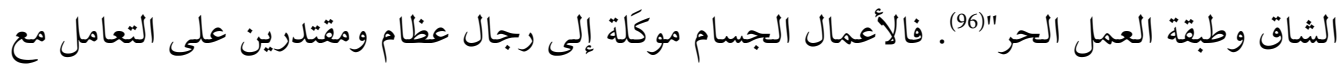

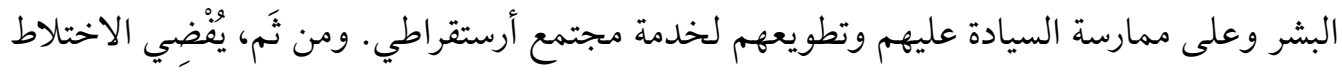

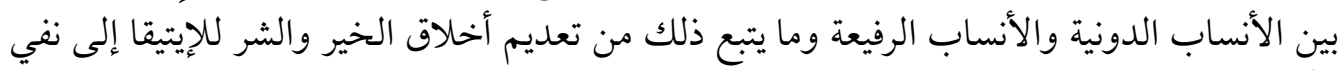

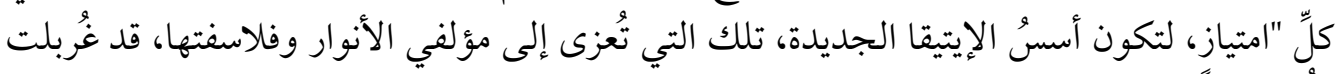

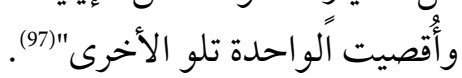

إن الاعتبار الإيتيقي القائمَ على حماية مظهر النبل والرفعة لدى خاصة الناس هو ما يستدعي الاحتجاج

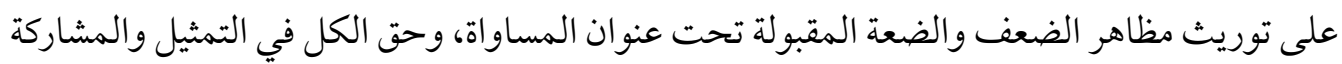

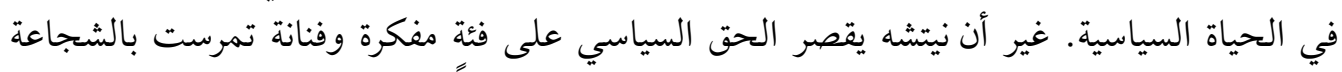

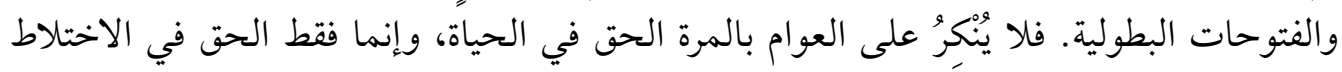

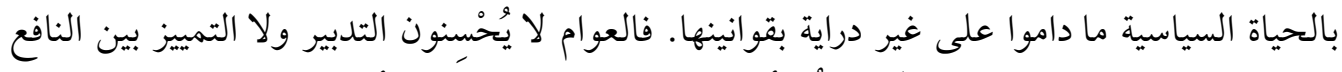

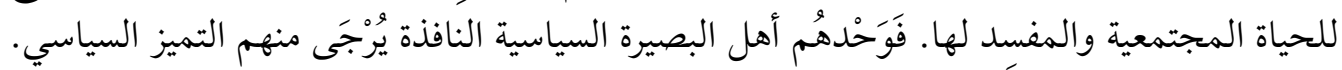

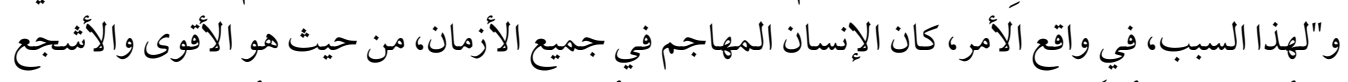

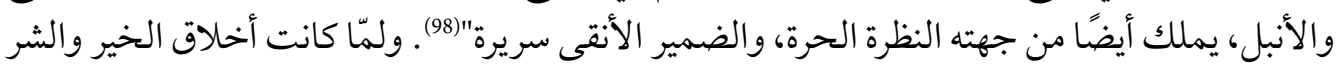

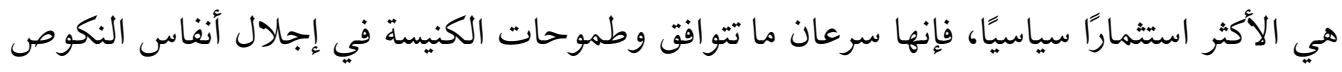

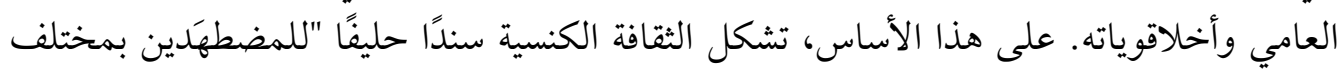

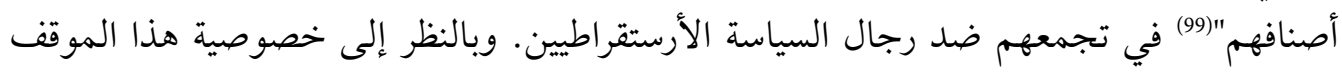

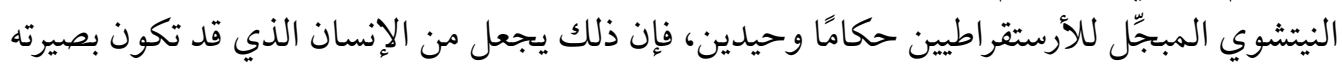

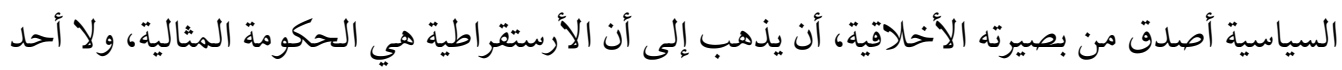

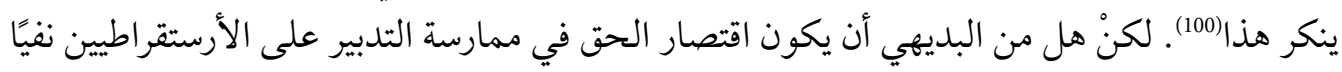
للعدالة؟

(95) Nietzsche, Fragments posthumes, vol. 13, p. 132.

(96) Nietzsche, Humain, trop humain, § 439, p. 264.

(97) Jacques Domenech, L'éthique des Lumières: Les fondements de la morale dans la philosophie française du XVIII'me siècle (Paris: Vrin, 1989), p. 14.

$$
\text { نيتشه، في جنيالوجيا الأخلاق، فقرة 11، ص } 103 .
$$

(99) Nietzsche, Fragments posthumes, vol. 13, p. 144.

(100) ول ديورانت، قصة الفلسفة: من أفلاطون إلى جون ديوي، حياة وآراء أعاظم رجال الفلسفة في العالم، ترجمة فتح الله محمد

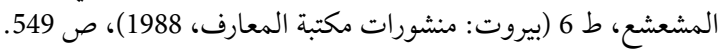




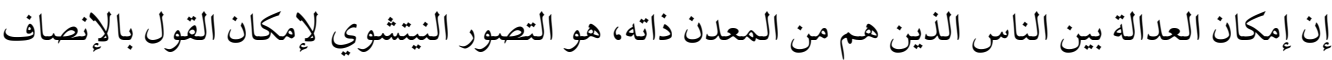

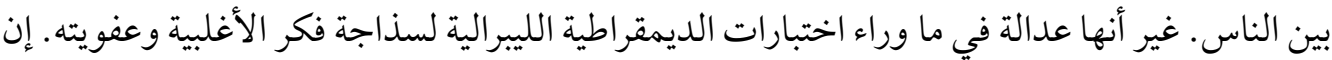

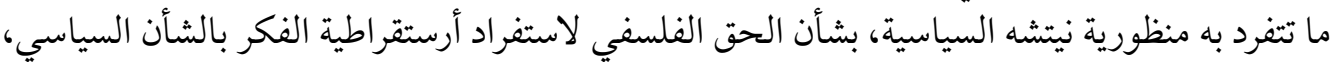

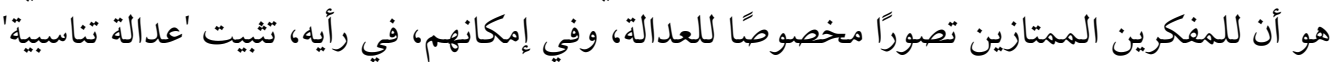

justice proportionnelle

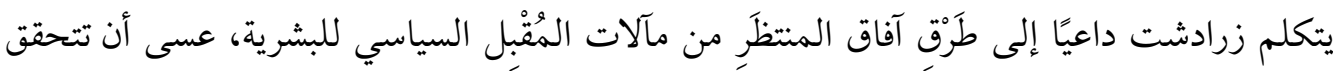

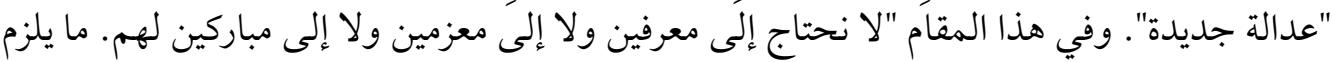

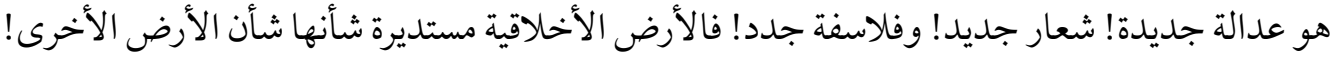

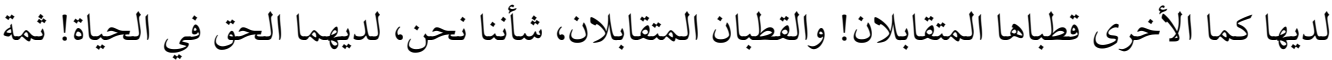

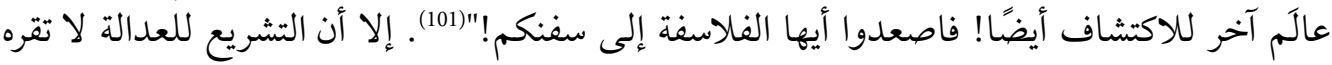
مقولة ليبرالية مجردة تستهدف إيهام الكل بتساويهم في الحقوق والواجبات أمام قوانين الدولة

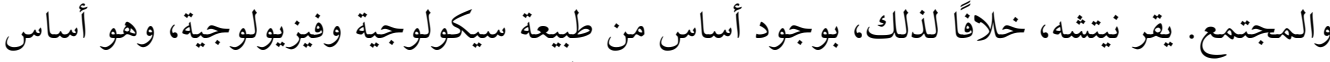

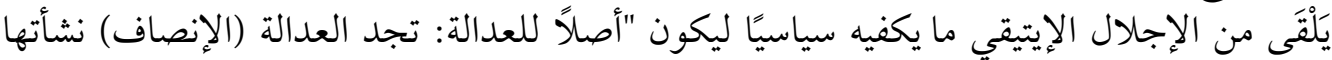

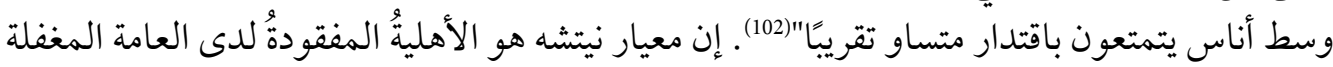

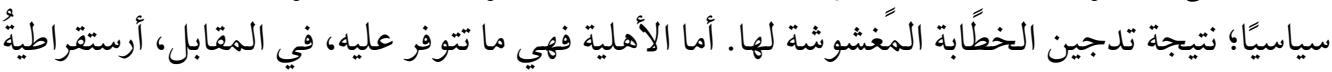

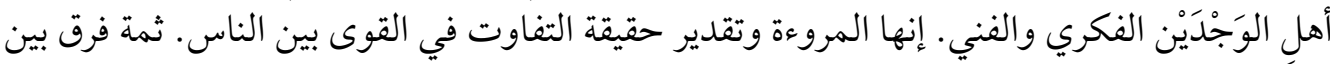

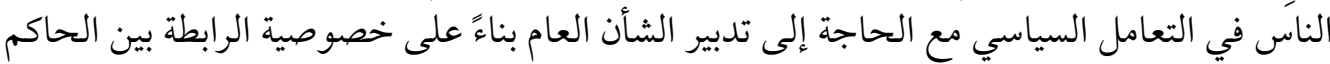

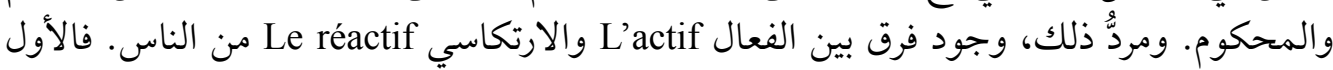

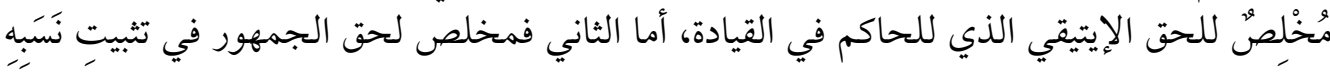

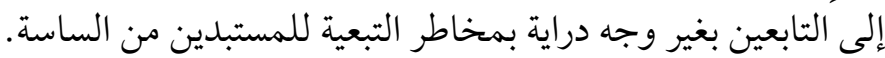

\section{خَاتمة}

"إن الإنسان الفاعل، المعتدي، الجائر، إنما يقف على الدوام، أقرب مئة خطوة إلى العدالة من الإنسان

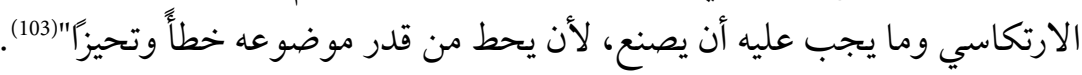

ما الخلاصة الفلسفية السياسية التي يمكننا استنتاجها من اعتبار نيتشه للديمقراطية عَرَجًا سياسيًّا مردهُ

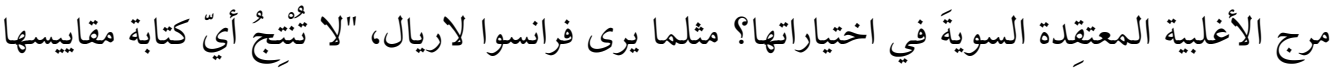
السياسية المحايثة مثل تلك التي لنيتشه"(104). نسوق هذه الخلاصة في نتيجتيْن أساسيتَّن استنادًا إلى فئى نيتشه، وثالثة يدعمها موقف أحد كبار منظري الديمقراطية الحديثة:

$$
\text { (101) يتشه، العلم الجذل، فقرة 289، ص } 158 .
$$

(102) Nietzsche, Humain, trop humain, § 92, p. 88.

$$
\text { نيتشه، في جنيالوجيا الأخلاق، فقرة 11، ص } 103 .
$$

(104) François Laruelle, Nietzsche contre Heidegger: Thèses pour une politique nietzschéenne (Paris: Payot, 1977), p. 27. 


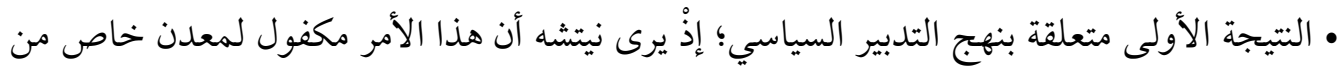

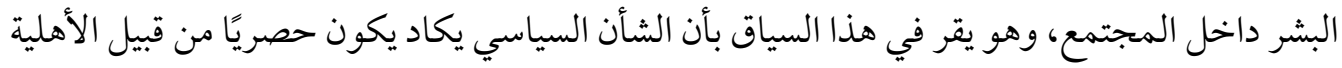

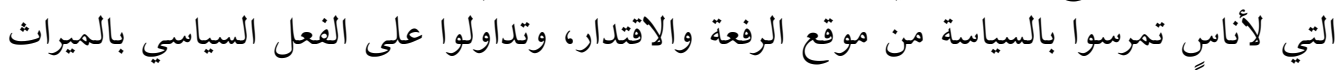

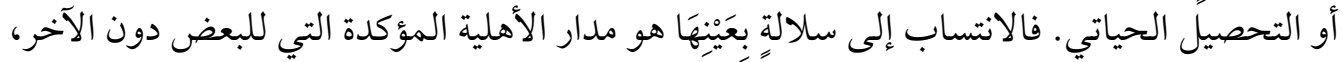

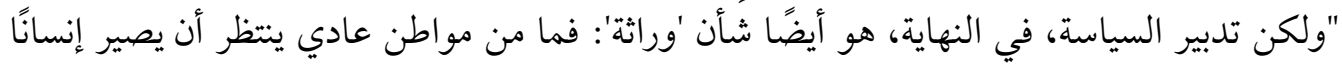
متمتعًا بأفت غير محدود" (105).

• النتيجة الثانية، وهي دعامة للأولى، تقوم على إنكار نيتشه للصيغة التمثيلية في البرلمانات المنتخَبة.

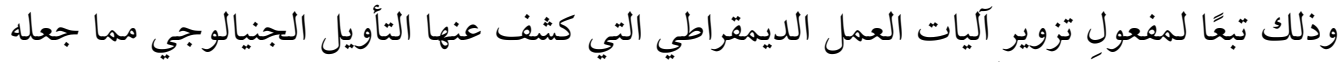

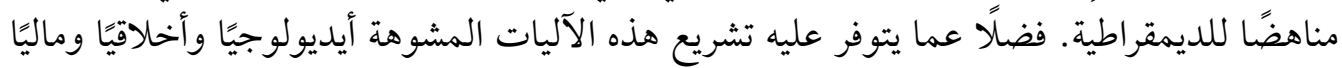

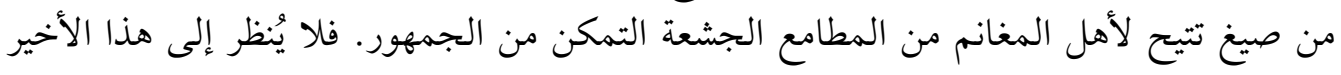

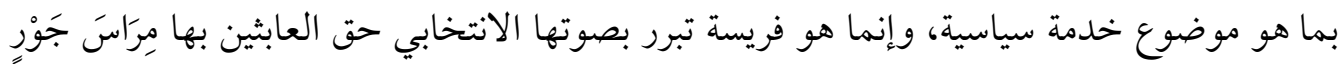

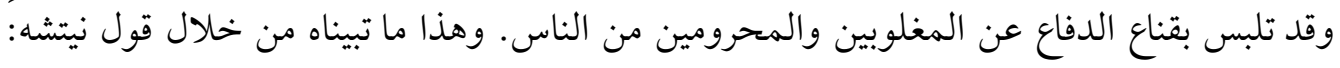

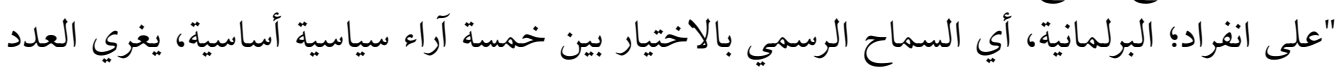

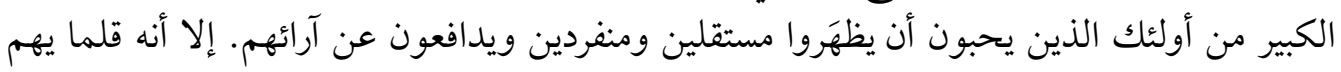

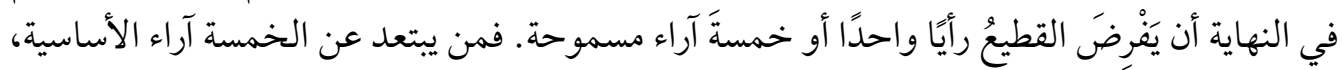

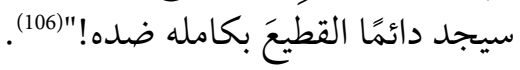

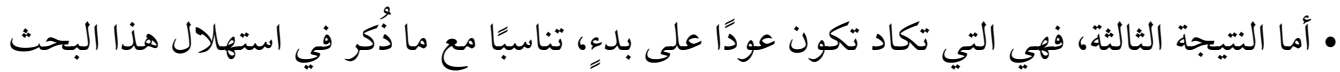

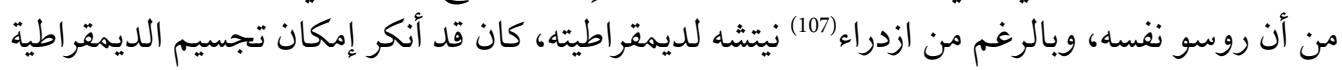

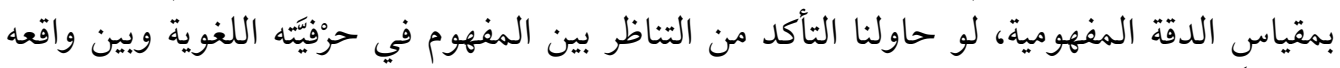

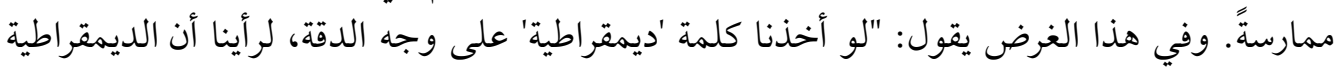

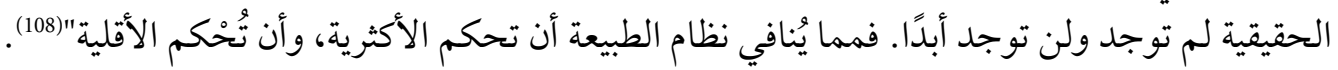

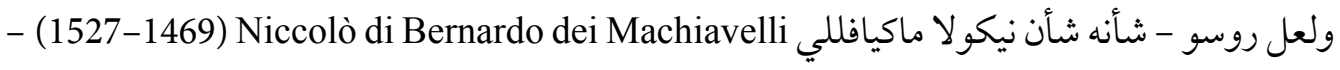
غير غافل عن دلالة الأرستقراطية الفكرية المحمولة على الأقلية - النخبة.

\section{References} أفلاطون. جمهورية أفلاطون. ترجمة فؤاد زكريا. الإسكندرية: دار الوفاء لدنيا الطباعة والنشر، 2004. أوديف، ستيبان. على دروب زرادشت. ترجمة فؤاد أيوب. دمشق: دار دمشق، 1983. (105) Nietzsche, Fragments posthumes, vol. 11, pp. 185-186. 
بلعقروز، عبد الرزاق. نيتشه ومهمة الفلسفة: قلب تراتب القيم والتأويل الجمالي للحياة. تقديم عز العرب لحكيم بناني. الجزائر: منشورات الاختلاف؛ بيروت: الدار العربية للعلوم ناشرون، 2010. ديورانت، ول. قصة الفلسفة: من أفلاطون إلى جون ديوي، حياة وآراء أعاظم رجال الفلسفة في العالم. ترجمة فتح الله محمد المشعشع. ط 6. بيروت: منشورات مكتبة المعارف، 1988. رانسيير، جاك. كراهية الديمقراطية. ترجمة أحمد حسان. بيروت: دار التنوير للطباعة والنشر والتوزيع، .2012

روسو، جان-جاك. في العقد الاجتماعي: أو مبادئ الحق السياسي. ترجمة عمار الجلاصي وعلي الأجنف. تونس: دار المعرفة للنشر، 1980. شميت، كارل. اللاهوت السياسي، ترجمة رانية الساحلي وياسر الصاروط. الدوحة/ بيروت: المركز العربي للأبحاث ودراسة السياسات، فوكوياما، فرانسيس. نهاية التاريخ والإنسان الأخير. ترجمة فؤاد شاهين وجميل قاسم ورضا الشايبي. بيروت: مركز الإنماء القومي، 1993. الكواكبي، عبد الرحمن. طبائع الاستبداد ومصارع الاستعباد. تقديم أسعد السحمراني. ط 2. بيروت: دار النفائس للطباعة والنشر والتوزيع، 1986. نيتشه، فريدريتش. الفلسفة في العصر المأساوي الإغريقي. ترجمة سهيل القش. تقديم ميشال فوكو. بيروت: المؤسسة الجامعية للدراسات، 1983. العلم الجذل. ترجمة سعاد حرب. بيروت: دار المنتخب العبي للدراسات والنشر والتوزيع، 2001.

ـ ما وراء الخير والشر: تباشير فلسفة للمستقبل. ترجمة جيزيلا فالور حجار . مراجعة موسى وهبة. بيروت: دار الفارابي؛ الجزائر: المؤسسة الوطنية للاتصال والنشر والإشهار، 2003. . هذا هو الإنسان. ترجمة علي مصباح. كولونيا: منشورات الجمل، 2003. هكذا تكلم زرادشت: كتاب للجميع ولغير أحد. ترجمة علي مصباح. كولونيا/ بغداد: منشورات الجمل، • في جنيالوجيا الأخلاق. ترجمة فتحي المسكيني. مراجعة محمد محجوب. تونس: المركز الوطني للترجمة، 2010. غست الأوثان: أو كيف نتعاطى الفلسفة قرَعًا بالمطرقة. ترجمة علي مصباح · بيروت/ بغداد: منشورات الجمل، 2010. • نقيض المسيح: مقال اللعنة على المسيحية. ترجمة علي مصباح · بيروت/بغداد: منشورات

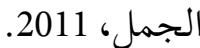
. الفجر. ترجمة محمد الناجي. الدار البيضاء: أفريقيا الشرق، 2013. 
Astor, Dorian. Deviens ce que tu es: Pour une vie philosophique. Paris: Autrement, 2016.

Beardsworth, Richard. Nietzsche. Paris: Les belles lettres, 1997.

Cioran, Emil Michel. Précis de décomposition. Paris: Gallimard, 2007.

Clair, André. Éthique et humanisme: Essai sur la modernité. Paris: Cerf, 1989.

De Tocqueville, Alexis. De la Démocratie en Amérique. Collection: Bouquins. Paris: Robert Laffont, 1986.

Domenech, Jacques. L'éthique des Lumières: Les fondements de la morale dans la philosophie française du XVIII ${ }^{\grave{m} e}$ siècle. Paris: Vrin, 1989.

Kremer-Marietti, Angèle. Thèmes et structures dans l'œuvre de Nietzsche. Paris: Les cahiers des lettres modernes, 1957.

Krulic, Brigitte. "Nietzsche et la critique de la modernité démocratique." Archives de Philosophie: Recherches et Documentation. vol. 64, no. 2 (2001).

. Nietzsche penseur de la hiérarchie: Pour une lecture "tocquevillienne"de Nietzsche. Collection: Ouverture philosophique. Paris: L'Harmattan, 2002.

Laruelle, François. Nietzsche contre Heidegger: Thèses pour une politique nietzschéenne. Paris: Payot, 1977.

Lefranc, Jean. Comprendre Nietzsche. Paris: Armand Colin, 2003.

"Nietzsche. L'antisystème." Philosophie Magazine. Hors-série. vol. 26 (été 2015).

Nietzsche, Friedrich. Sämtliche Werke: Kritische Studienausgabe in 15 Bänden. Giorgio Colli \& Mazzino Montinari (eds.). Munich: Deutscher Taschenbuch Verlag, 1980.

. Fragments posthumes: Automne 1884 - automne 1885. Michel Haar \& Marc Buhot De Launay (trad.). Giorgio Colli \& Mazzino Montinari (eds.). Euvres philosophiques complètes. vol. 11. Paris: Gallimard, 1982.

. Ecce Homo: Wie man wird, was man ist, XIII: Der Fall Wagner-Ein Musikanten-Problem. Giorgio Colli \& Mazzino Montinari (eds.). Sämtliche Werke, Kritische Studienausgabe. $6^{\text {th }}$ ed. Berlin $/$ New York: Deutscher Taschenbuch Verlag; München: Walter de Gruyter, 1988.

. Humain, trop humain: Un livre pour esprits libres. Robert Rovini (trad.). Giorgio Colli \& Mazzino Montinari (eds.). Euvres philosophiques complètes. vol. 3. Paris: Gallimard, 1988.

. Fragments posthumes: Été 1872-Hiver 1873-1874. Pierre Rusch (trad.). Euvres philosophiques complètes. vol. 2. Paris: Gallimard, 1990.

. Le livre du philosophe: Études théorétiques. Angèle Kremer-Marietti (trad.). Paris: Garnier Flammarion, 1991.

. Ainsi parlait Zarathoustra: Un livre qui est pour tous et qui n'est pour personne. Maurice De Gandillac (trad.). Euvres philosophiques complètes. vol. 6. Paris: Gallimard, 2004. 
. Crépuscule des Idoles ou Comment philosopher à coups de marteau. Jean-Claude Hémery (trad.). CEuvres philosophiques complètes. vol. 8. Paris: Gallimard, 2004.

Par-delà bien et mal: Prélude d'une philosophie de l'avenir, Cornélius Heim, Isabelle Hildenbrand \& Jean Gratien (trad.). CEuvres philosophiques complètes. vol. 7. Paris: Gallimard, 2006.

Fragments posthumes: Automne 1887-mars 1888. Pierre Klossowski \& Henri-Alexis Baatsch (trad.). Euvres philosophiques complètes. vol.13. Paris: Gallimard, 2006.

. Fragments posthumes: Automne 1885 -automne 1887. Julien Hervier (trad.). Euvres philosophiques complètes. vol. 12. Paris: Gallimard, 2007.

Fragments posthumes: Début 1888-début janvier 1889. Jean-Claude Hémery (trad.). CEuvres philosophiques complètes. vol. 14. Paris: Gallimard, 2008.

Fragments posthumes: Été 1869-Printemps 1872. Michel Haar, Philippe Lacoue-Labarthe \& Jean-Luc Nancy (trad.). CEuvres philosophiques complètes, vol. 1. Paris: Gallimard, 2008.

Reboul, Olivier. Nietzsche critique de Kant. Paris: PUF, 1974.

Souchon, Gisèle. Nietzsche: Généalogie de l'individu. Paris: L'Harmattan, 2003.

Tzitzis, Stamatios. Nietzsche et les hierarchies. Paris: L'Harmattan, 2008.

Valadier, Paul. Nietzsche: Cruauté et noblesse du droit. Paris: Michalon, 1998.

Wotling, Patrick. Le vocabulaire de Friedrich Nietzsche. Paris: Ellipses, 2007. 